\title{
Hepatitis B Virus-induced modulation of liver macrophage function promotes hepatocyte infection
}

Suzanne Faure-Dupuy ${ }^{1,2, \$}$, Marion Delphin ${ }^{1, \$}$, Ludovic Aillot ${ }^{1}$, Laura Dimier ${ }^{1}$, Fanny Lebossé ${ }^{1,3}$, Judith Fresquet ${ }^{1}$, Romain Parent ${ }^{1}$, Matthias Sebastian Matter ${ }^{4}$, Michel Rivoire ${ }^{5}$, Nathalie Bendriss-Vermare ${ }^{1}$, Anna Salvetti ${ }^{1}$, Danijela Heide ${ }^{2}$, Lalo Flores ${ }^{6}$, Klaus Klumpp ${ }^{6}$, Angela Lam $^{6}$, Fabien Zoulim ${ }^{1,3,7}$, Mathias Heikenwälder ${ }^{2}$, David Durantel ${ }^{1,7,+, *}$, and Julie Lucifora ${ }^{1,+, *}$

${ }^{1}$ INSERM, U1052, Cancer Research Center of Lyon (CRCL), Université de Lyon (UCBL1), CNRS UMR_5286, France ;

${ }^{2}$ Division of Chronic Inflammation and Cancer, German Cancer Research Center (DKFZ), Heidelberg, Germany;

${ }^{3}$ Department of Hepatology, Croix-Rousse Hospital, Hospices Civils de Lyon, Lyon, France;

${ }^{4}$ University Hospital of Basel, Institute of Pathology, Basel, Switzerland;

${ }^{5}$ INSERM U1032, Centre Léon Bérard (CLB), Lyon, France ;

${ }^{6}$ Novira therapeutics; part of the Janssen Pharmaceutical Companies;

${ }^{7}$ DEVweCAN Laboratory of Excellence, Lyon, France;

\$authors contributed equally;

${ }^{+}$authors contributed equally;

*Corresponding authors:

Dr. Julie Lucifora and Dr. David Durantel

Centre de Recherche en Cancérologie de Lyon (CRCL), UMR Inserm 1052 - CNRS 5286, 151 cours Albert Thomas, 69424 Lyon Cedex 03, France ; Phone: + 33472681970 ; Fax : +33 472681971 ; E-mail: julie.lucifora@inserm.fr and david.durantel@inserm.fr

Key words: Liver macrophage, hepatitis B virus (HBV), phenotypic immune-modulation, IL$1 \beta$, IL-10, anti-inflammatory, anti-viral effect.

Electronic word count of the main text: 6327

\section{Number of figures: 9 \\ Number of supplementary figures: 10 \\ Number of tables: 7}

\section{Competing financial interest:}

SFD, MD, LA, LD, JF, FL, RP, MR, NBV, MH have nothing to declare. FZ, JL, and DD received a research grant from Novira Therapeutics to perform experiments. AL, LF and KK were employees of Novira Therapeutics.

\section{Financial support statements:}

This work was supported by grants from ANRS (French national agency for research on AIDS and viral hepatitis), FINOVI (Foundation for innovation in infectiology), ARC (French Agency for Research against Cancer), Novira Therapeutics and INSERM. This work was also supported by the DEVweCAN LABEX (ANR-10-LABX-0061) of the "Université de Lyon", within the program "Investissements d'Avenir" (ANR-11-IDEX-0007) operated by the French National Research Agency (ANR). M.H. was supported by an ERC Consolidator grant (HepatoMetaboPath), the SFBTR 209 and SFBTR179 and the Helmholtz-Gemeinschaft, Zukunftsthema "Immunology and Inflammation" (ZT-0027). This project has received funding from the European Union's Horizon 2020 research and innovation program under grant agreement No 667273. 
Author contributions statements:

55 - study concept and design: SFD, MD, JL, DD

56 - acquisition of data: SFD, MD, LA, LD, JF, DH, MH

57 - analysis and interpretation of data: SFD, MD, AL, KK, JL, DD

58 - drafting of the manuscript: SDF, JL, DD

59 - critical review of the manuscript: AL, KK, NBV, FZ, MH

60 - statistical analyses: SFD

61 - material support: MR, NBV, FL, RP, MSM, FZ, 


\section{ABSTRACT}

Background and aims. Liver macrophages can be both involved in pathogen clearance and/or pathogenesis. To get further insight on their role during chronic hepatitis B virus (HBV) infections, our aim was to phenotypically and functionally characterize in vivo and ex vivo the interplay between HBV, primary human liver macrophages (PLM) and primary blood monocytes differentiated into pro-inflammatory or anti-inflammatory macrophages (M1-MDM or M2-MDM, respectively).

Results. We evidenced the presence of HBc protein within macrophages in liver biopsies from HBV-infected patients and higher levels of anti-inflammatory macrophages markers, compared to non-infected ones. Ex vivo exposure of naive PLM to HBV led to a reduced secretion of proinflammatory cytokines. Upon exposure to HBV or HBV-producing cells during differentiation and activation, M1-MDM secreted less IL-6 and IL-1 $\beta$, whereas M2-MDM secreted more IL-10 when exposed to HBV during activation. Finally, cytokines produced by M1-MDM, but not those produced by HBV-exposed M1-MDM, decreased HBV infection of hepatocytes.

Conclusions. Altogether, our data strongly suggest that HBV modulates liver macrophage functions to favour its establishment.

Lay summary: HBV modulates liver macrophages function in order to favour its establishment and likely its maintenance. It impairs the production of the antiviral cytokine IL- $1 \beta$ while promoting that of IL-10 in the microenvironment. This phenotype can be recapitulated in naive liver macrophages or monocytes-derived-macrophages ex vivo by short exposure to the virus or cells replicating the virus, thus suggesting an "easy to implement" mechanism of inhibition. 


\section{Introduction}

Hepatitis B virus (HBV) chronically infects around 250 million people worldwide (WHO data, 2016) and increases the risk of developing cirrhosis and hepatocellular carcinoma ${ }^{1}$. Current treatments, mainly based on nucleos(t)ide analogues, reduce blood viremia to undetectable levels in the majority of patients, but do not achieve virus elimination from the liver ${ }^{2}$. New treatments, including immune-therapeutic components, are therefore needed in order to progress toward a functional cure for HBV.

$\mathrm{HBV}$ is a small DNA virus that persists as a covalently-closed-circular DNA (cccDNA) within the nucleus of liver parenchymal cells (hepatocytes). Viral RNAs, including mRNAs and the pre-genomic RNA (pgRNA) are transcribed from the cccDNA. The pgRNA is encapsulated within the nucleocapsid and converted into relaxed-circular DNA (rcDNA) by an HBV polymerase-mediated reverse-transcription step. Different viral products circulate in the blood of infected patients including HBe antigens (HBeAg), Dane particles (infectious particles), HBV RNA containing particles and empty (i.e., nucleocapsid free) enveloped subviral particles (SVPs). The latter three have envelope proteins at their surface and are indistinctly detected as HBs antigens (HBsAg) ${ }^{2}$. SVPs, which are produced in large excess compared to virions, are thought to play an important role in terms of immune subversion ${ }^{3}$.

Several pro-inflammatory cytokines (IL-6, IL-1 $\beta$ and TNF $\alpha$ ) and interferons (IFNa and IFNY) were shown to induce a direct antiviral effect on HBV replication in hepatocytes ${ }^{4-7}$, with IL-1 $\beta$ being one of the most efficient at inhibiting already established HBV infections in vitro ${ }^{4}$. IL-1 is a pro-inflammatory cytokine produced upon inflammasome activation ${ }^{8}$. In the liver, it is mostly produced by macrophages $(M \Phi)$ since hepatocytes do not possess functional inflammasomes ${ }^{9,10}$. Liver resident $M \Phi$, named Kupffer cells $(K C)$, represent $80 \%$ of the macrophage count in the body at steady state ${ }^{11}$. They are specialized in the detection of pathogens coming from the enteric circulations, as well as in the elimination of aging blood cells, through their high phagocytic capacity ${ }^{11}$. Upon inflammation, monocytes from the blood 
111 circulation can be recruited in the liver and differentiate locally into $\mathrm{M} \Phi$ that are called

112 monocyte-derived-macrophages (MDM) ${ }^{12} . \mathrm{KC}$ and MDM have different embryonic origins and

113 functions ${ }^{13}$. In vivo, a wide range of different phenotypes of $М \Phi$ exists depending on their 114 origin, activation status, localization, and their micro-environment ${ }^{14}$. Inflammatory МФ,

115 commonly called $\mathrm{M} 1$, which are phenotypically described as $\mathrm{CD} 40^{+} \mathrm{CD}^{+} 6^{+} \mathrm{HLA}-\mathrm{DR}{ }^{+}$, are 116 characterized by their capacity to secrete pro-inflammatory cytokines/chemokines, such as IL-

$1171 \beta$, produce various antimicrobial factors, including nitric oxide (NO), and are therefore 118 implicated in inflammation and elimination of pathogens ${ }^{14}$. Anti-inflammatory $М \Phi$, commonly 119 called M2, express the arginase 1, mannose receptors, and the high affinity scavenger receptor 120 CD163, and secrete anti-inflammatory cytokines, such as IL-10 and TGF $\beta$, as well as 121 angiogenic factors, such as VEGF ${ }^{14}$. M2 MФ are involved in the resolution of inflammation 122 and in tolerance mechanisms ${ }^{14}$. They are also abundantly found in tumour microenvironment 123 and are called tumour-associated $\mathrm{M} \Phi\left(\right.$ TAM $^{15}$.

124 Several studies showed that HBV can influence the phenotype and biology of $M \Phi^{16}$, but few 125 have been performed using liver resident or infiltrating primary human cells. To get further 126 insights into the role of liver MФ in the establishment of HBV infection in hepatocytes, we used 127 highly relevant model such as primary human liver $\mathrm{M} \Phi$, pro-inflammatory/M1-like or anti128 inflammatory/M2-like MФ differentiated in vitro from primary blood monocytes, liver biopsies, 129 primary human hepatocytes (PHH), differentiated HepaRG cells (dHepaRG), and co-culture 130 models. 


\section{MATERIALs AND METHODS}

Patient samples. Two different cohorts were analysed. The collection and analysis of human patient samples of the first cohort (Swiss/German cohort) was approved by the ethics committee of Northern Switzerland (EKNZ, Study ID: PB_2018-00308, 310/12), confirmed to the ethical guidelines of the 1975 Declaration of Helsinki, and was provided by the Department of Pathology, Basel, Switzerland. The biopsies were stained in Germany. Patients' characteristics are presented in Table S1. Samples from the second cohort were used under the French IRB 'CPP Sud-Est IV' approval \#11/040 (2011) from the 'Biobanque INSERM CRCL Hépatologie (U1052)', France \#DC2008-235 and stained in France. Written informed consent was obtained from each patient. Patients' characteristics are presented in Table S2.

Immunohistochemistry. Paraffin was removed from FFPE samples by successive alcohol bathes and epitopes were unmasked as previously described ${ }^{17}$. Endogen peroxidases were blocked by a 15 min exposition at room temperature with Dual Endogenous enzyme Block (DAKO S2003). Saturation was performed by two successive incubations at RT of 20 min with horse serum (VECTOR S-2012 Za0328) and 15 min with DAKO antibody diluent (DAKO S3022). Antibodies (Table S3) were incubated overnight at $4^{\circ} \mathrm{C}$ in DAKO antibody diluent. Samples were incubated for $15 \mathrm{~min}$ at RT with secondary antibodies (Table S3). Coloration was performed with DAB substrate (DAKO K3468) or permanent red substrate (DAKO K0640), and counterstaining with haematoxylin (SIGMA MHS1). Negative controls were performed using control IgGs (Table S3) or non-infected patients, and no staining was observed (Figure S1). Optical density ( $O D=\log$ (max intensity/mean intensity)) of the $D A B$ staining was quantified using Fiji (ImageJ) and the results are presented as 1/OD. For the CD68, HBcAg double staining, a BONDMax robotic staining machine (Leica) was used.

Primary cells purification and cells culture. Peripheral blood mononuclear cell (PBMC) from blood donors (Etablissement Français du Sang, EFS; code 895/1052) were isolated by Ficoll gradient (Histopaque ${ }^{\circledR}-1077$, Sigma) as previously described ${ }^{18}$. Lymphocytes were separated from total PBMC by a Percoll gradient and further cultured in macrophage medium (RPMI 
medium supplemented with $10 \%$ of decomplemented FBS and $50 \mathrm{U} / \mathrm{mL}$ of penicillin/streptomycin). Monocytes were purified by Percoll gradient followed by a negative selection with the Monocyte Isolation Kit II (Miltenyi Biotec) and cultured in macrophage medium. Monocytes were exposed during 6 days to $50 \mathrm{ng} / \mathrm{mL}$ of GM-CSF (R\&D) or $50 \mathrm{ng} / \mathrm{mL}$ of M-CSF from (Peprotech) for M1-MDM or M2-MDM differentiation respectively. MDM were activated by a 3-hours stimulation with $10 \mathrm{ng} / \mathrm{mL}$ of LPS (Invivogen). Cells were washed three times with PBS and cultured in fresh medium for another 3 hours before a last medium exchange. Supernatants and cells were collected $24 \mathrm{~h}$ post stimulation (i.e. $18 \mathrm{~h}$ accumulation). Liver cells were isolated from hepatic resections obtained in collaboration with three surgical departments of Lyon (Centre Léon Bérard, Hôpital de la Croix Rousse and centre hospitalier Lyon-Sud) with the French ministerial authorizations (AC 2013-1871, DC 2013-1870, AFNOR NF 96900 sept 2011). After a two-step collagenase perfusion, the liver extract was filtered and centrifuged, as previously described ${ }^{19}$. Primary Human Hepatocytes $(\mathrm{PHH})$ were cultured on collagen layer and maintain in $\mathrm{PHH}$ medium (Williams medium supplemented with $5 \%$ of fetal clone II serum, $50 \mathrm{U} / \mathrm{mL}$ of penicillin/streptomycin, $1 \mathrm{X}$ glutamax, $5 \mu \mathrm{g} / \mathrm{mL}$ of bovine insulin, $5 \times 10^{-5} \mathrm{M}$ of hydrocortisone, and $2 \%$ of DMSO). Liver mononuclear cells (LMNC) or only liver MФ were purified from the non-parenchymal cells mixture by respectively Ficoll gradients or a two phase iodixanol gradient ${ }^{20}$. Liver $M \Phi$ were isolated by negative selection using pan monocyte isolation kit (Miltenyi Biotec) and cultured in macrophage medium. HepaRG cells were cultured and differentiated as previously described ${ }^{21}$.

Viral infection. Differentiated HepaRG (dHepaRG) or PHH were cultured and infected by HBV (PEG-precipitated) as previously described ${ }^{22}$. As PEG-concentrated HBV virions cannot be used for exposition to immune cells, because PEG activates cells, blood monocytes, LMNC and liver MФ were exposed to HBV inocula (or control medium), which were prepared by concentrating supernatant from HepAD38 ${ }^{23}$ (or from non-infected HepG2-NTCP respectively) by filtration/retention centrifugation using column with a cut off retention of $100 \mathrm{kDa}$ (Merk Millipore; UFC710008). All virus inoclula were tested for the absence of endotoxin (Lonza) and 
characterized by analyses of the fractions from a $5.6-56 \%$ iodixanol gradient and analysed by ELISA, dot blot with HBV DIG-labelled probe ${ }^{24}$ and western-blot (DAKO, B0586) (Figure S2). This allowed to rule out the presence of non-enveloped nucleocapsids that may activate immune cells, as HBc was shown to be a TLR2 ligand ${ }^{25}$. Blood monocytes, LMNC and liver $M \Phi$ were exposed to at least three different batches of HBV (full inoculum concentrated by ultrafiltration) at a multiplicity of infection of $1000 \mathrm{vge} / \mathrm{mL}$ (if not stated otherwise). Viral titer superior to $10^{10} \mathrm{vge} / \mathrm{mL}$ were routinely obtained and uniquely used in order to allow a dilution of 100 to 1000 fold when preparing "infection medium" at a multiplicity of infection of 1000 vge/cell. This way, we limited the impact of "carried-away" contamination. For some experiments, virus was inactivated by a 30 min exposition to UVB. Stocks of adenoviruses (AAV) vector particles were generated by the vector Core of the University of Nantes by calcium phosphate transfection of HEK-293 cells as described previously using pDG8 (as a helper plasmid). The vector particles were purified on caesium chloride gradients as previously described ${ }^{26}$ and genome particles $/ \mathrm{mL}$ (gp/mL) were tittered by quantitative PCR (qPCR). AAV at a multiplicity of infection of $1000 \mathrm{gp} / \mathrm{mL}$.

Cytochalasin D and cytokine treatments. M2-MDM were exposed to $1 \mu \mathrm{g} / \mathrm{mL}$ of Cytochalasin D (Sigma Aldrich; C8273-1MG) during their activation. As Cytochalasin D is diluted in DMSO, monocytes were exposed to a similar dose of DMSO as control. Cytokines references and used concentration are indicated in Table S4.

Quantification of secreted proteins by ELISA. HBeAg and HBsAg secretion were quantified using chemiluminescence immunoassay kit (Autobio) following the manufacturer's instructions. Cytokines secretion were analysed using Duoset ELISA (R\&D system) following manufacturer's instructions.

RNA extraction and RT-qPCR. Total mRNA from hepatocytes or MФ were extracted with NucleoSpin ${ }^{\circledR}$ RNA II or NucleoSpin® RNA XS respectively (Macherey-Nagel). cDNA were synthetized using the SuperScript@III Reverse Transcriptase (Life technologies) according to the manufacturer's instructions. qPCR analyses were performed using "Express SYBR 
212 GreenER ${ }^{\mathrm{TM}}$ qPCR SuperMix Universal" (Invitrogen). mRNA expression was assessed by 213 comparative cycle threshold (Ct) method (2-ACt); GUS and RPLPO were used as housekeeping 214 genes for hepatocytes and MФ respectively. Primers sequences are presented in Table S5.

215 DNA extraction and cccDNA quantification. Total DNA were extracted using the NucleoSpin® Tissue kit (Macherey-Nagel) following the manufacturer's instructions. Total intracellular DNA was digested for $45 \mathrm{~min}$ at $37^{\circ} \mathrm{C}$ with $\mathrm{T} 5$ exonuclease (epicentre) to remove rcDNA (relaxed circular HBV DNA) followed by a 30 min heat inactivation. cccDNA amount was quantified by qPCR analyses as previously described ${ }^{1}$.

Cytotoxicity assay. Seven days post treatments, hepatocytes cell viability was assessed by quantification of neutral red uptake by living cells, as previously described ${ }^{4}$.

Lymphocytes activation. Lymphocytes were cultured in different M2-MDM conditioned media at a density of 300,000 cells $/ \mathrm{cm}^{2}$ for 2 hours. Cells were activated by a $22 \mathrm{~h}$ exposition to 20 $\mathrm{ng} / \mathrm{mL}$ of Phorbol 12-Myristate 13-Acetate (Sigma) and $500 \mathrm{ng} / \mathrm{mL}$ of lonomycine. Activation was measured by assessment of TNF- $\alpha$ secretion.

Macrophage supernatants concentration. M1- or M2-MDM supernatants from at least five different donors were pooled and concentrated by ultrafiltration (using $10 \mathrm{kDa}$ Amicon ultra-15 column; Merk-Millipore) following the manufacturer's instruction. Cytokines concentration of the concentrated supernatants were assessed by ELISA before dilution to $1 / 100$ in hepatocyte media (experiments from Figure 9) or dilution to 1/2 in macrophages media (experiments from Figure 7). Final concentrations are presented in Table S6 and S7.

Flow cytometry. Cells were washed extensively with PBS and removed from plate with 150 $\mu \mathrm{l}$ of versene-EDTA at $37^{\circ} \mathrm{C}$ for $5 \mathrm{~min}$ before centrifugation at $1300 \mathrm{rpm}$ for $5 \mathrm{~min}$ at $4^{\circ} \mathrm{C}$. Cells were incubated for $30 \mathrm{~min}$ at $4^{\circ} \mathrm{C}$ with primary antibody (Table S3). After extensive washes, cells were incubated with secondary antibody in the dark for 30 min at $4^{\circ} \mathrm{C}$. After another wash, staining was measured by Flow Cytometry (BD FACSCALIBUR). 
237 Statistical analysis. Results are presented as mean or median \pm standard deviation and 238 analysed for statistical significance using Prism software. P values are indicated and non239 significance is indicated by "ns". 


\section{RESULTS}

$H B V$ is associated with phenotypic changes in liver macrophages in infected patients.

242

To assess if HBV may closely interact with liver M $\phi$ in vivo, levels of CD68 expression (identifying $M \Phi), C D 163$ (identifying anti-inflammatory $M \Phi^{14}$ ) and $\mathrm{HBc}$ (identifying the HBV core protein) were analysed by immunochemistry on liver biopsies from two distinct cohorts of patients (see Table S1 and S2 for details on patients). As expected, signals for CD68, CD163 were detected in the sinusoidal space (i.e., in between hepatocytes where myeloid cells are), and no signals were observed with control antibodies (Figure 1 and S1). Co-localized signals were observed for $\mathrm{HBc}$ and $\mathrm{CD} 68$ in liver samples from HBV infected patients (Figure 1A and zoom in Figure 1B) evidencing the presence of this HBV protein within liver МФ. Of note, the proportion of $\mathrm{M} \phi$ co-stained with $\mathrm{HBc}$ varied from one patient to the other; approximatively $20 \%$ of all patients analysed lacked co-localisation between $\mathrm{HBc}$ and $\mathrm{M} \phi, 50 \%$ displayed less than $5 \%$ co-localisation, and $30 \%$ showed between $5 \%$ to $20 \%$ co-localisation (Figure 1A, zoom in Figure 1B). Furthermore, quantification of the signals highlighted a 1.8 fold increase in $\mathrm{CD}_{163^{+}}$myeloid cells in HBV-infected patient $(+79 \%, \mathrm{p}=0.0271)$ in the Swiss/German cohort and a 1.3 fold increase in the French cohort compared to the non-infected ones (Figure 1C, 1D, S1B). Interestingly, a positive correlation between the level of $\mathrm{HBc}$ staining and the increase of $C D 163^{+}$cells was observed (Figure 1E). Altogether, these data suggest that HBV interact with liver $\mathrm{M} \Phi$ and may affect their phenotype and functions. We therefore performed several ex vivo analyses to investigate the influence of HBV on liver cells with a focus on liver $M \Phi$ that include Kupffer cells (KC) and monocyte derived MФ (MDM) ${ }^{9,10}$.

\section{Ex vivo, $H B V$ inhibits the activation of primary liver $M \Phi$ by direct exposure.}

First, we investigated the impact of HBV particles and antigens (concentrated by filtration/retention from HepAD38 cell supernatants and characterized as shown on Figure S1) 
on the secretion of cytokines by non-parenchymal primary human liver mononuclear cells (LMNC) freshly isolated from hepatic resections (5 donors) as previously described ${ }^{27}$. Of note, we used a virus concentrated by filtration/retention rather than PEG concentration, as PEG per se activates macrophages. The basal levels of two prototypic cytokines, namely IL-1 $\beta$ and IL10, in non-stimulated LMNC from individual donors are shown in Figure $\mathbf{2 A}$. These cells were either left untreated or exposed for 24 hours to total HBV inoculum immediately after their isolation and the same cytokines were dosed in the supernatant (Figure 2B). The mean concentration of secreted IL-1 $\beta$ was $25 \%$ lower in HBV exposed LMNC preparations as compared to control whereas the mean IL-10 level was 64\% higher (Figure 2B).

Purified primary liver MФ (PLMФ) exposed to HBV or not were next stimulated with synthetic PAMPs; LPS was used to stimulates TLR4 and NLRP3 (NOD-like receptor family, pyrin domain containing 3) inflammasome ${ }^{28}$, whereas LPS + poly(dA:dT) was used to stimulate TLR4 and AIM-2 (Absent In Melanoma-2) inflammasome ${ }^{9}$ (Figure 2C). The mean level of secreted IL$1 \beta$ was $31 \%$ lower in LPS-stimulated PLMФ exposed to HBV, as compared to not exposed condition (Figure 2D). Similar results were obtained with HBV exposed, LPS and poly(dA:dT)stimulated PLMФ, for which the mean level of secreted IL-1 $\beta$ was $35 \%$ lower (Figure 2E). Interestingly, the expression of HIF1 $\alpha$ mRNA, which encode a protein tightly associated to IL$1 \beta$ production and secretion in macrophages ${ }^{29}$, was $70 \%$ lower in LPS-stimulated-PLM $\Phi$ exposed to HBV as compared to control (Figure S3). While the mean level of secreted IL-10 was not affected by HBV with both types of stimulations in our experimental conditions (Figure 2D and 2E), the mRNA levels of VEGF, an angiogenic factor expressed by anti-inflammatory cells ${ }^{30}$, was $56 \%$ higher in LPS-stimulated-PLMФ exposed to HBV, as compared to control cells (Figure S3).

Altogether these data suggest that HBV may interfere with the activation of PLMФ. 
292 During viral infections, a high quantity of immune cells, among which monocytes, are recruited to the inflammation/injury site to mount a strong pro-inflammatory response and contribute to infection control ${ }^{31}$. This response is subsequently limited by an anti-inflammatory response in order to start the scarring processes and prevent chronic inflammation ${ }^{31}$. Infiltrating monocytes differentiate into $\mathrm{M} \Phi$ within the tissue ${ }^{14}$ and, in the case of the human liver, cannot be fully distinguished from resident $M \Phi$.

To assess the effect of HBV on $M \Phi$ that experimentally mimic those derived from liver infiltrating monocytes, monocytes were purified from peripheral blood mononuclear cells (PBMC) and differentiated, with well-established polarizing in vitro conditions, into M1-like MФ (M1-MDM) upon GM-CSF or M2-like MФ (M2-MDM) upon M-CSF stimulation ${ }^{32}$. The differentiation process is schematically presented in Figure 3A. M1-MDM cells derived from peripheral monocytes expressed and secreted, under a physiologic exposure to LPS (10 $\mathrm{ng} / \mathrm{mL}$ ), pro-inflammatory cytokines IL-6, IL-1 $\beta$, and TNF- $\alpha$, but not IL-10 (Figure 3B, 3C, 3D, and 3E). In contrast, in vitro differentiated M2-MDM cells expressed only residual levels of IL6 , IL-1 $\beta$, and TNF- $\alpha$, but secreted high level of the anti-inflammatory cytokine IL-10 in the same condition of physiologic LPS exposure (Figure 3B, 3C, 3D, and 3E). Upon exposure to HBV during differentiation and activation (i.e., 6 days exposure to HBV) (Figure 3A), GM-CSFtreated monocytes (i.e., intended to be differentiated into M1-MDM) activated with low LPS stimulation, secreted $34 \%$ and $60 \%$ less IL-6 and IL- $1 \beta$ respectively (Figure $3 F$ ). Accordingly, a decreased level of HIF1a mRNA was detected (Figure S4A). Under these conditions, no significant effect of HBV incubation was observed on the level of secreted TNF- $\alpha$ (Figure 3F). M2-MDM exposed to HBV during differentiation and activation secreted similar level of IL-10 than non-exposed cells (Figure 3G) but expressed lower VEGF mRNAs levels (Figure S4A). 
We further investigated the effect of HBV on the activation of already differentiated M1-MDM or M2-MDM in response to physiologic LPS stimulation (Figure 4A). No difference was observed in the mean levels of secreted IL-6, IL-1 $\beta$, or TNF- $\alpha$ (Figure 4B). In contrast, lower mean mRNA level of HIF1- $\alpha$ was observed (Figure S4B). Differentiated M2-MDM cells showed a 2-fold increase of mean secreted IL-10 levels and an increase of mean VEGF mRNA levels in the presence of HBV (Figure S4B). These results were confirmed with different donors and duration of exposure to HBV (Figure S5). Moreover, increasing doses of HBV inoculum revealed increasing effect i) on the inhibition of IL-6 secretion by M1-MDM, exposed to the virus during their differentiation and activation, and ii) on the increase of IL-10 secretion by M2-MDM, exposed to the virus during their activation (Figure $5 \mathbf{A}$ and $5 B$ ).

Interestingly, the presence of cytochalasin D (Cyt D, an inhibitor of endocytosis and phagocytosis ${ }^{33}$ ), during the activation of M2-MDM in the presence of HBV did not modify IL10 secretion (Figure $5 \mathrm{C}$ ), suggesting that the effect of HBV on M2-MDM activation might be independent of virus productive entry within macrophages. It is also worth noting that UVinactivated HBV has a similar effect on PLM $\Phi$ (Figure S6A) and on M1- and M2-MDM (Figure S6B) secretions as compared to replication-component HBV, and that HBV-exposed liver MФ or MDMs did not secrete HBeAg or HBsAg (Figure S7), highlighting that the effects of HBV on $M \Phi$ is independent of viral replication within cells. Moreover, no significant modification of cytokine secretion was observed when M1- or M2-MDM were exposed to concentrated supernatants from non-infected HepG2-NTCP during, respectively, their differentiation and activation or activation only (Figure S6C and S6D), suggesting that the effect is specific to HBV and not to a factor secreted by hepatocytes in the absence of HBV. Finally, adenoviruses (AAV), either expressing GFP or HBV genome, had no effect on M1-MDM secretions (Figure 5D), suggesting that the observed effect is specific of HBV particles and/or antigens. Of note, the cells exposed to AAV-HBV did not secreted HBeAg or HBsAg (data not shown). 

conditions

To exclude that the effect of secreted HBV components on M1-MDM differentiation and M2MDM activation was due to the high amount of HBV experimentally used in previously presented ex vivo experiments, we set up co-cultures assays that allowed to study the effect of HBV components physiologically secreted from infected hepatocytes. Monocytes, which were intended to differentiate into M1-MDM and M2-MDM, were co-cultured with either noninfected HepG2-NTCP cells (as HBV negative control cells) or with HBV-producing HepAD38 cells during their respective differentiation (for M1-MDM) or activation (for M2-MDM) (Figure 6A). We confirmed the results obtained with cell free derived viruses and observed an even stronger effect of HBV since monocytes co-cultured with HBV-producing cells during their differentiation into M1-MDM, secreted between 46 and $85 \%$ lower mean levels of IL-6, IL-1 $\beta$, and TNF- $\alpha$ (Figure 6B). In contrast, M2-MDM co-cultured with HBV producing cells during their activation secreted 2.25-fold more IL-10 (Figure 6C).

Altogether these results suggest that exposure of peripheral monocytes to cell-free HBV and also cell-transmitted HBV components can interfere with their differentiation into M1-MDM, as indicated by the significantly reduced secretions of pro-inflammatory cytokines, including IL1ß. Moreover, an exposure to HBV during M2-MDM activation led to an increased secretion of the anti-inflammatory cytokine IL-10.

\section{HBV impairs lymphocyte activation.}

$\mathrm{IL}-10$ is well-known to impair lymphocyte activation ${ }^{34}$. Therefore, we assessed if increase of IL-10 secretion induced by HBV (Figure 4C) would further impair this activation. Total lymphocytes were purified from peripheral blood and exposed to M2-MDM conditioned media for $2 \mathrm{~h}$ before their activation with Phorbol 12-Myristate 13-Acetate (PMA) + ionomycine. Even though not significant, total lymphocytes exposed to M2-MDM supernatants secreted $17 \%$ less 
TNF- $\alpha$ than the non-exposed ones (Figure 7, (no-HBV M2-MDM)-CM). Supernatants from M2-MDM exposed to HBV during their activation containing higher amounts of IL-10 (Figure 4C and Table S6, (HBV stim M2-MDM)-CM) significantly decreased TNF- $\alpha$ secretion (30\%) by total lymphocytes (Figure 7).

Pro-inflammatory cytokines reduce the establishment of HBV infection in hepatocytes.

As previously shown, pro-inflammatory cytokines can directly block HBV replication in cells persistently infected in vitro and IL-1 $\beta$ was the most efficient ${ }^{4}$. To investigate the effects of $M \Phi$-derived cytokines on the establishment of HBV infection in hepatocytes, dHepaRG cells or primary human hepatocytes $(\mathrm{PHH})$ were treated $24 \mathrm{~h}$ before and during the inoculation of cells with HBV with various recombinant pro-inflammatory cytokines (rhlL-1 $\beta$, rhIL-6, rhTNF- $\alpha$, rhlL-18), anti-inflammatory cytokines (rhIL-10, rhTGF $\beta$ ), as well as with rhMCP-1, which is known to be secreted by both M1- and M2-MФ (Table S4) ${ }^{35}$. RhIL-1 $\beta$ treatment led to a 70$80 \%$ decrease of $\mathrm{HBeAg}$ and $\mathrm{HBsAg}$ secretion, HBV mRNA, and cccDNA formation, under conditions where cell viability of dHepaRG cells and PHH were not affected (Figure 8). Of note, a $24 \mathrm{~h}$ pre-treatment with rhIL-1 $\beta$, followed by a withdrawal during HBV inoculation, was sufficient to decrease HBeAg and HBsAg secretion and HBV mRNA by $75 \%$ in dHepaRG (Figure S8A). In addition, treatment with rhIL-6 and rhTNF- $\alpha$ before and during HBV inoculation resulted in an approximately $50 \%$ decrease of $\mathrm{HBeAg}, \mathrm{HBV}$ RNA, and cccDNA formation. HBsAg was lowered by $\sim 50 \%$ with rhTNF- $\alpha$ and by $\sim 25 \%$ with rhlL- 6 treatment (Figure S8B). rhlL-18 had no effect on the establishment of HBV infection under these conditions (Figure S8B). Upon rhIL-10 treatment, we observed a slight increase of mean HBeAg and HBsAg levels in the supernatant of dHepaRG cells, but not in PHH. HBV RNA was modestly reduced in $\mathrm{PHH}$ treated with $\mathrm{IL}-10$ before and during infection (Figure 8B). Other tested cytokines, TGF- $\beta$ and MCP-1, had no significant effect on the establishment of HBV infection (Figure S8B). Of note, we calculated that around $250 \mathrm{pg} / \mathrm{mL}$ of rhlL-1 $\beta$ and $25 \mathrm{ng} / \mathrm{mL}$ 
of rhTNFa are necessary to obtain a $50 \%$ decrease of the establishment of HBV infection (Figure S9) whereas no further decrease was obtained with $20 \mathrm{ng} / \mathrm{mL}$ of rlL-6 (Figure S9) and no still no effect with increasing doses of rhIL-10 (Figure S9). Importantly, if the level of NTCP (sodium-taurocholate co-transporting polypeptide), the HBV receptor, was decreased in dHepaRG after $24 \mathrm{~h}$ or $48 \mathrm{~h}$ of treatment with IL-1 $\beta$ (Figure S10A), it was not affected in PHH (Figure S10B), indicating that the measured anti-HBV effect was not uniquely due to hNTCP expression modulation. Collectively, these data indicate that pro-inflammatory cytokines, and IL-1 $\beta$ in particular, are very efficient to inhibit the establishment of HBV infection in hepatocytes.

We next investigated whether cell culture supernatants from M1-MDM cells exposed or not with HBV would interfere with the establishment of HBV infection in hepatocytes. Even though, the final concentrations of IL-1 $\beta$ and IL- 6 were respectively 25 fold and 10 fold lower compared to the concentration of recombinant cytokines used above (Figure 8), treatment of dHepaRG cells with supernatants from differentiated M1-MDM cells (Table 4 and 7) inhibited HBV establishment as shown by a reduction of the mean $\mathrm{HBeAg}$ and $\mathrm{HBsAg}$ levels by $\sim 25 \%$ (Figure 9, (no-HBV M1-MDM)-CM). Accordingly, dHepaRG treated with supernatants from M1-MDM exposed to HBV during activation, that contained similar amounts of pro-inflammatory cytokines to non-exposed M1-MDM (Figure 4B and Table S7), showed a 40\% decrease of secreted HBV antigens (Figure 9, (HBV stim M1-MDM)-CM). In contrast, dHepaRG treated with concentrated supernatants from M1-MDM exposed to HBV during differentiation, containing less pro-inflammatory cytokines (Figure 3F and Table S7), showed similar levels of HBV markers to those measured in non-treated dHepaRG (Figure 9, (HBV diff M1-MDM)CM).

Altogether, these data suggest that the pro-inflammatory secretome derived from M1-MDM can inhibit the establishment of HBV infection in hepatocytes. In addition, this antiviral effect is lost when monocytes are exposed to HBV during their differentiation. 


\section{DISCUSSION}

419 Dendritic cells and $\mathrm{M} \Phi$ in the liver are thought to play a major role in the orchestration of 420 adaptive responses and can also produce cytokines that may directly affect HBV infection ${ }^{36}$. 421 We confirmed here that cytokines secreted by pro-inflammatory $\mathrm{M} \Phi$ (including IL-1 $\beta$ and IL-6) 422 strongly inhibit the establishment of HBV infection in hepatocytes. These results are in agreement with our previously reported data showing antiviral effects of these cytokines in already infected human hepatocytes ${ }^{4}$ and emphasize the potential direct role of proinflammatory cytokines in the control of HBV. Of note, even though we observed a decrease in the level of NTCP in dHepaRG treated with IL-1 $\beta$ as previously reported ${ }^{37}$, NTCP levels were not changed by $\mathrm{IL}-1 \beta$ treatment in primary human hepatocytes $(\mathrm{PHH})$ under conditions that were sufficient for HBV inhibition. These results suggest that IL-1 $1 \beta$ can inhibit HBV establishment through an NTCP-independent but still ill-defined molecular mechanism.

Considering the antiviral potential of liver $М \Phi$ derived cytokines, the main scope of this study was to investigate if HBV could interfere with such macrophage pro-inflammatory functions to facilitate the establishment of hepatocyte infection. Using human primary cells, we observed (i) that primary liver MФ (PLMФ) exposed ex vivo to HBV secrete less pro-inflammatory cytokines upon synthetic PAMP stimulations, thus confirming our previously published data ${ }^{8}$, (ii) that M1-MDM also secrete less IL-1 $\beta$ and IL-6 upon activation if exposed to HBV or HBVproducing cells during differentiation and (iii) that the antiviral effect of M1-MDM conditioned medium is lost when cells were differentiated in the presence of HBV. These results are in accordance with those from previously published studies using animal models or macrophage cell lines that reported an ability of HBV to inhibit macrophage responses ${ }^{9,38-41}$, and further demonstrate that HBV has evolved strategies to interfere with liver myeloid cells functions, in

441 the absence of any bona fide replication (i.e. neo-synthesis of viral genome and proteins) in 442 these cells. 
Importantly, this phenotype was similar in naive liver macrophages or monocytes-derivedmacrophages ex vivo by short exposure to the virus or cells replicating the virus, thus suggesting an "easy to implement" mechanism of inhibition, again irrespective of a proper replication of HBV in these cells. In addition, we showed that the inhibition of pro-inflammatory cytokines and increase of anti-inflammatory cytokines is dependent on the quantity of virus. However, to be maintained, such an inhibitory phenotype would require a constant exposure to the virus and/or viral components. In this respect, our data showing an increased inhibition of the secretion of pro-inflammatory cytokines by M1-MDM upon constantly renewed exposure to HBV via co-cultures with HBV-producing cells compared to a single exposure to concentrated virus support the latest hypothesis. In contrast, the recent study by Suslov and colleagues convincingly showed that the stimulation with synthetic PAMPS (including TLR4 ligands) was not antagonized in ex vivo cultivated HBV-positive biopsies ${ }^{42}$. In this case, the purification procedure and ex vivo conditions cultures in the absence of HBV virion or viral components might have reversed the HBV-inhibitory phenotype. Moreover, additional experimental pitfalls could explain these opposite results. First, the concentration of TLR4 ligands used in this study was far higher to what used here $(20 \mu \mathrm{g} / \mathrm{mL}$ versus 10 to $100 \mathrm{ng} / \mathrm{mL})$ and probably beyond physiologic conditions. Moreover, despite the commendable effort of this study to work with highly relevant biological materials, the viability of hepatocytes in these ex vivo maintained biopsies was limited and the viability as well as the functionality of other liver cells such as liver macrophages was not assessed. It would therefore be important to test if the addition of $\mathrm{HBeAg} / \mathrm{HBsAg} / \mathrm{HBV}$ virions in the culture medium of ex vivo cultured liver biopsies and the use of physiologic levels of stimulations would recapitulate the inhibitory phenotype we described here.

Importantly, we observed an increase of anti-inflammatory MФ markers (CD68 ${ }^{+} \mathrm{CD}_{163^{+}}$cells) in liver biopsies from HBV-infected patients compared to those from non-infected patients of two different cohorts and an increase in the levels of IL-10 secreted by M2-MDM upon exposure to HBV during activation after ex vivo differentiation. These data suggest that HBV 
may reinforce the already described liver immune tolerance ${ }^{16}$ to establish and/or maintain its infection. This is in accordance with studies reporting an increase of anti-inflammatory cytokine secretion (especially IL-10) induced by HBV in animal models and patients ${ }^{43-46}$ and a positive role of anti-inflammatory liver M $\Phi$ in HBV persistence ${ }^{43}$. Here, we observed that HBV-induced increase of IL-10 secretion by M2-MDM might impair the activation of lymphocytes. As others had previously described ${ }^{43,47,48}$, the increased IL-10 expression during HBV infection could favour a tolerogenic environment and the inhibition of functional adaptive immune response, compromising HBV elimination. As these anti-inflammatory $\mathrm{M} \Phi$ are also implicated in affecting distinct oncogenetic processes (through the secretion of angiogenic factors, such as VEGF, and the impairment of an anti-oncogenic responses by the secretion of regulatory mediators, such as IL-10 ${ }^{49}$ ), it should be investigated if the HBV-induced modification of МФ phenotypes may also play a role in HCC initiation and promotion.

We did not precisely determine which viral components and which HBV-infection related mechanisms influence cytokine secretion by $М \Phi$. The secreted viral proteins (HBeAg, $\mathrm{HBsAg}$ ) or viral proteins contained in virions (HBsAg, $\mathrm{HBc}$, viral polymerase) may play a role in the modification of $M \Phi$ phenotype. Few data suggest that HBV can be internalized by $M \Phi(29,44)$. $\mathrm{HBeAg}{ }^{10}$, HBsAg ${ }^{9,40}$ and the HBV capsid protein ${ }^{52}$ have been suggested to contribute to the inhibition of $\mathrm{M} \Phi$ responses. In the present study, analyses of liver biopsies from HBV infected patient revealed a co-localisation between $\mathrm{HBc}$ and a macrophage marker (CD68; $\mathrm{HBcAg}$ ). How $\mathrm{HBc}$ is delivered to liver macrophages remained to be addressed; it could be through a specific receptor, unspecific engulfment, or by phagocytosis of dying infected hepatocytes. Moreover, it is not clear yet in which subcellular compartment (e.g. organelles; lysosomes) stained HBcAg is located.

Of note, the use of recombinant viral proteins to clarify the involvement of viral proteins in the modification of $\mathrm{M} \Phi$ responses may be suboptimal, as post-transcriptional modifications associated to a given protein produced in a given cell system (bacteria, yeast or mammalian cells) could be different as compared to those found in viral proteins from infected hepatocytes 
and therefore have a different effect on immune cells. In addition, these modifications may vary during the different phases of HBV infection, giving the numerous functions of the viral proteins. HBV probably interferes with the activation of $M \Phi$ (and thereby cytokine secretion) at different levels. Indeed down-regulation of innate sensors such as TLR ${ }^{41,53,54}$ or inhibition of cell different signaling pathways ${ }^{39,40,47}$ have been reported. Epigenetic modulations induced by the fixation of one viral protein to gene promoters, as reported in hepatocytes ${ }^{52}$ and as also reported for other viruses ${ }^{55-57}$ might also be implemented in $М \Phi$ even though HBV do not replicate in those cells. Importantly, the different effects observed are specific of HBV as AAVs had no impact on M1- and M2-MDM secretions. Our data suggest that HBV productive entry into cells (i.e. with fusion of membrane between viral particles and cells) may not be absolutely required to induce phenotypic changes in macrophages. One of several viral proteins present in the inoculum or circulating in blood of patients (HBsAg and $\mathrm{HBeAg}$ ) may bind to receptor(s) of macrophages involved in modulation of inflammatory responses. As described before, the activation of specific regulatory receptors at the surface of macrophages can trigger inhibition of pro-inflammatory cytokines secretion ${ }^{58-60}$. It will therefore be important to determine the target(s) of HBV at the surface of macrophages responsible for the modulations observed in order to develop specific molecules targeting this interaction.

Importantly, in our different experimental settings, we did not detect any cytokine secretion by LMNC, primary human liver macrophages or MDM exposed to cell-culture-produced HBV inocula or co-cultured with HBV producing cells (data not shown). This is in sharp contrast with chronic HCV or HIV infections that induces strong host responses ${ }^{61-64}$ but in accordance with studies that reported an absence of measurable innate immune responses in patients, animal or in vitro models upon primary HBV infection ${ }^{42,45,62,65-67}$ and contributed to define HBV as a stealth virus ${ }^{68}$. Of course, as also shown here, this stealthy character could be due to active evasion and not complete passivity. In contrast, several groups have reported an induction of innate responses following exposure to $\mathrm{HBV}^{7,25,50,69,70}$. The quality of the $\mathrm{HBV}$ inoculum used to perform the ex vivo analyses is probably very different from one study to the other since no 
standard inocula are available and only very few manuscripts reported the characterization of their inocula as we did here (Figure S2). Indeed, different HBV producing cells, different culture conditions and concentration procedures may lead to different ratios of viral antigens, subviral particles and Dane particles as well as contaminating non-enveloped nucleocapsids, recognized by TLR2 ${ }^{25}$ or endotoxins, recognized by TLR4 ${ }^{71}$ in the inocula and may explain the discrepancies between the studies.

From a therapeutic point of view, we here confirmed that IL-1 $\beta$ is very efficient to inhibit HBV establishment and replication in hepatocytes. However, recombinant IL-1 $\beta$ cannot be used systemically without risking severe side effects such as cytokine storms. New anti-HBV therapeutic options should aim at inducing the local and endogenous secretion of IL-1 $\beta$ to induce an antiviral activity and prevent the development of pathogenesis. Different strategies may be considered to promote pro-inflammatory over anti-inflammatory phenotype in liver resident and infiltrating $\mathrm{M \Phi}$. For instance, the delivery of GM-CSF in cancerous tissue has been shown to induce tumour regression ${ }^{72,73}$ by promoting pro-inflammatory macrophages. Inversely, a monoclonal antibody against CSF-1R (colony stimulating factor 1 receptor) showed promising results in reducing the number of anti-inflammatory and tumour associated macrophages ${ }^{15}$. Alternatively, inhibitors of glutaminolysis, that modify the succinate/aketoglutarate balance in macrophages ${ }^{74}$ or specific inflammasome and/or PRR inducers could be evaluated ${ }^{75}$.

In summary, we showed that HBV can modulate the resident and transiting-macrophage phenotypes to favour its establishment, and likely its maintenance in the liver. On the one hand, HBV escapes the antiviral effect of pro-inflammatory liver resident and infiltrating $М \Phi$ by interfering with their activation/differentiation and inhibiting the production of cytokines endowed with anti-HBV activities. Besides, HBV infection promotes the activation of antiinflammatory $M \Phi$ and the production of IL-10 in the microenvironment to probably favour tolerance. Our data also suggest that therapeutic strategies promoting the differentiation of pro-inflammatory liver $\mathrm{M} \Phi$ over anti-inflammatory ones or the shift from one to the other should 
551 be tested to help breaking immune tolerance and promoting a functional cure of chronic HBV

552 infections. 


\section{REFERENCES}

554 1. Werle-Lapostolle, B. et al. Persistence of cccDNA during the natural history of chronic hepatitis B 555 and decline during adefovir dipivoxil therapy. Gastroenterology 126, 1750-1758 (2004).

556 2. Durantel, D. \& Zoulim, F. New antiviral targets for innovative treatment concepts for hepatitis B virus and hepatitis delta virus. J. Hepatol. 64, S117-131 (2016).

3. Ait-Goughoulte, M., Lucifora, J., Zoulim, F. \& Durantel, D. Innate antiviral immune responses to hepatitis B virus. Viruses 2, 1394-1410 (2010).

4. Isorce, N. et al. Antiviral activity of various interferons and pro-inflammatory cytokines in nontransformed cultured hepatocytes infected with hepatitis B virus. Antiviral Res. 130, 36-45 (2016).

5. Palumbo, G. A. et al. IL6 Inhibits HBV Transcription by Targeting the Epigenetic Control of the Nuclear cccDNA Minichromosome. PloS One 10, e0142599 (2015).

6. Xia, Y. et al. Interferon- $\gamma$ and Tumor Necrosis Factor- $\alpha$ Produced by T Cells Reduce the HBV Persistence Form, cccDNA, Without Cytolysis. Gastroenterology 150, 194-205 (2016).

7. Hösel, M. et al. Not interferon, but interleukin-6 controls early gene expression in hepatitis B virus infection. Hepatol. Baltim. Md 50, 1773-1782 (2009).

8. Broz, P. \& Dixit, V. M. Inflammasomes: mechanism of assembly, regulation and signalling. Nat. Rev. Immunol. 16, 407-420 (2016).

9. Zannetti, C. et al. Characterization of the Inflammasome in Human Kupffer Cells in Response to Synthetic Agonists and Pathogens. J. Immunol. Baltim. Md 1950 197, 356-367 (2016).

10. $\mathrm{Yu}, \mathrm{X}$. et al. HBV inhibits LPS-induced NLRP3 inflammasome activation and IL-1 $\beta$ production via suppressing the NF-KB pathway and ROS production. J. Hepatol. 66, 693-702 (2017).

11. Krenkel, O. \& Tacke, F. Liver macrophages in tissue homeostasis and disease. Nat. Rev. Immunol. 17, 306-321 (2017).

12. Scott, C. L. et al. Bone marrow-derived monocytes give rise to self-renewing and fully differentiated Kupffer cells. Nat. Commun. 7, 10321 (2016). 
13. Ginhoux, F. \& Guilliams, M. Tissue-Resident Macrophage Ontogeny and Homeostasis. Immunity 44, 439-449 (2016).

14. Hume, D. A. The Many Alternative Faces of Macrophage Activation. Front. Immunol. 6, 370 (2015).

15. Ries, C. H. et al. Targeting tumor-associated macrophages with anti-CSF-1R antibody reveals a strategy for cancer therapy. Cancer Cell 25, 846-859 (2014).

16. Yuan, F., Zhang, W., Mu, D. \& Gong, J. Kupffer cells in immune activation and tolerance toward HBV/HCV infection. Adv. Clin. Exp. Med. Off. Organ Wroclaw Med. Univ. 26, 739-745 (2017).

17. Bollard, J. et al. Antitumor effect of everolimus in preclinical models of high-grade gastroenteropancreatic neuroendocrine carcinomas. Neuroendocrinology 97, 331-340 (2013).

18. Combes, A. et al. BAD-LAMP controls TLR9 trafficking and signalling in human plasmacytoid dendritic cells. Nat. Commun. 8, (2017).

19. Lecluyse, E. L. \& Alexandre, E. Isolation and culture of primary hepatocytes from resected human liver tissue. Methods Mol. Biol. Clifton NJ 640, 57-82 (2010).

20. Hösel, M. et al. Toll-like receptor 2-mediated innate immune response in human nonparenchymal liver cells toward adeno-associated viral vectors. Hepatol. Baltim. Md 55, 287297 (2012).

21. Gripon, P. et al. Infection of a human hepatoma cell line by hepatitis B virus. Proc. Natl. Acad. Sci. U.S. A. $99,15655-15660$ (2002).

22. Luangsay, S. et al. Early Inhibition of Hepatocyte Innate Responses by Hepatitis B Virus. J. Hepatol. (2015). doi:10.1016/j.jhep.2015.07.014

23. Iwamoto, M. et al. Evaluation and identification of hepatitis B virus entry inhibitors using HepG2 cells overexpressing a membrane transporter NTCP. Biochem. Biophys. Res. Commun. 443, 808813 (2014).

24. Lucifora, J. et al. Detection of the hepatitis B virus (HBV) covalently-closed-circular DNA (cccDNA) in mice transduced with a recombinant AAV-HBV vector. Antiviral Res. 145, 14-19 (2017). 
25. Cooper, A., Tal, G., Lider, O. \& Shaul, Y. Cytokine induction by the hepatitis B virus capsid in macrophages is facilitated by membrane heparan sulfate and involves TLR2. J. Immunol. Baltim. Md 1950 175, 3165-3176 (2005).

26. Salvetti, A. et al. Factors influencing recombinant adeno-associated virus production. Hum. Gene Ther. 9, 695-706 (1998).

27. Faure-Dupuy, S. et al. Characterisation of Pattern Recognition Receptors (PRR) expression and functionality in liver primary cells and derived cell lines. submitted (2018).

28. Yi, Y.-S. Caspase-11 non-canonical inflammasome: a critical sensor of intracellular lipopolysaccharide in macrophage-mediated inflammatory responses. Immunology 152, 207-217 (2017).

29. O'Neill, L. A. J. A broken krebs cycle in macrophages. Immunity 42, 393-394 (2015).

30. Jetten, N. et al. Anti-inflammatory M2, but not pro-inflammatory M1 macrophages promote angiogenesis in vivo. Angiogenesis 17, 109-118 (2014).

31. Brempelis, K. J. \& Crispe, I. N. Infiltrating monocytes in liver injury and repair. Clin. Transl. Immunol. 5, e113 (2016).

32. Chistiakov, D. A., Myasoedova, V. A., Revin, V. V., Orekhov, A. N. \& Bobryshev, Y. V. The impact of interferon-regulatory factors to macrophage differentiation and polarization into M1 and M2. Immunobiology (2017). doi:10.1016/j.imbio.2017.10.005

33. Schliwa, M. Action of cytochalasin D on cytoskeletal networks. J. Cell Biol. 92, 79-91 (1982).

34. Fiorentino, D. F. et al. IL-10 acts on the antigen-presenting cell to inhibit cytokine production by Th1 cells. J. Immunol. 146, 3444-3451 (1991).

35. Mantovani, A. et al. The chemokine system in diverse forms of macrophage activation and polarization. Trends Immunol. 25, 677-686 (2004).

36. Crispe, I. N. Liver antigen-presenting cells. J. Hepatol. 54, 357-365 (2011). 
37. Le Vee, M., Gripon, P., Stieger, B. \& Fardel, O. Down-regulation of organic anion transporter expression in human hepatocytes exposed to the proinflammatory cytokine interleukin 1beta. Drug Metab. Dispos. Biol. Fate Chem. 36, 217-222 (2008).

38. Real, C. I. et al. Hepatitis B virus genome replication triggers toll-like receptor 3-dependent interferon responses in the absence of hepatitis B surface antigen. Sci. Rep. 6, 24865 (2016).

39. Wu, J. et al. Hepatitis B virus suppresses toll-like receptor-mediated innate immune responses in murine parenchymal and nonparenchymal liver cells. Hepatol. Baltim. Md 49, 1132-1140 (2009).

40. Wang, S. et al. Hepatitis B virus surface antigen selectively inhibits TLR2 ligand-induced IL-12 production in monocytes/macrophages by interfering with JNK activation. J. Immunol. Baltim. Md 1950 190, 5142-5151 (2013).

41. Visvanathan, K. et al. Regulation of Toll-like receptor-2 expression in chronic hepatitis B by the precore protein. Hepatol. Baltim. Md 45, 102-110 (2007).

42. Suslov, A., Boldanova, T., Wang, X., Wieland, S. \& Heim, M. H. Hepatitis B Virus Does Not Interfere with Innate Immune Responses in the Human Liver. Gastroenterology (2018). doi:10.1053/j.gastro.2018.01.034

43. Xu, L., Yin, W., Sun, R., Wei, H. \& Tian, Z. Kupffer cell-derived IL-10 plays a key role in maintaining humoral immune tolerance in hepatitis B virus-persistent mice. Hepatol. Baltim. Md 59, 443-452 (2014).

44. Li, M. et al. Kupffer Cells Support Hepatitis B Virus-Mediated CD8+ T Cell Exhaustion via Hepatitis B Core Antigen-TLR2 Interactions in Mice. J. Immunol. Baltim. Md 1950 195, 3100-3109 (2015).

45. Dunn, C. et al. Temporal analysis of early immune responses in patients with acute hepatitis B virus infection. Gastroenterology 137, 1289-1300 (2009).

46. Bility, M. T. et al. Hepatitis B virus infection and immunopathogenesis in a humanized mouse model: induction of human-specific liver fibrosis and M2-like macrophages. PLoS Pathog. 10, e1004032 (2014). 
47. Jiang, M. et al. Toll-like receptor-mediated immune responses are attenuated in the presence of high levels of hepatitis B virus surface antigen. J. Viral Hepat. 21, 860-872 (2014).

48. Li, H. et al. Hepatitis B virus particles preferably induce Kupffer cells to produce TGF- $\beta 1$ over proinflammatory cytokines. Dig. Liver Dis. Off. J. Ital. Soc. Gastroenterol. Ital. Assoc. Study Liver 44, 328-333 (2012).

49. Tang, X., Mo, C., Wang, Y., Wei, D. \& Xiao, H. Anti-tumour strategies aiming to target tumourassociated macrophages. Immunology 138, 93-104 (2013).

50. Boltjes, A. et al. Kupffer cells interact with hepatitis B surface antigen in vivo and in vitro, leading to proinflammatory cytokine production and natural killer cell function. J. Infect. Dis. 211, 12681278 (2015).

51. Tohidi-Esfahani, R., Vickery, K. \& Cossart, Y. The early host innate immune response to duck hepatitis B virus infection. J. Gen. Virol. 91, 509-520 (2010).

52. Gruffaz, M. et al. The nuclear function of Hepatitis B capsid (HBc) protein is to inhibit IFN response very early after infection of hepatocytes. Hepatology (Baltimore, Md.) 276A (2013).

53. Huang, Y.-W. et al. Reduced Toll-like receptor 3 expression in chronic hepatitis B patients and its restoration by interferon therapy. Antivir. Ther. 18, 877-884 (2013).

54. Lebossé, F. et al. Intrahepatic innate immune response pathways are downregulated in untreated chronic hepatitis B. J. Hepatol. 66, 897-909 (2017).

55. Sen, P., Ganguly, P. \& Ganguly, N. Modulation of DNA methylation by human papillomavirus E6 and E7 oncoproteins in cervical cancer. Oncol. Lett. 15, 11-22 (2018).

56. Bonnaud, E. M. et al. Borna disease virus phosphoprotein modulates epigenetic signaling in neurons to control viral replication. J. Virol. 89, 5996-6008 (2015).

57. Adhya, D. \& Basu, A. Epigenetic modulation of host: new insights into immune evasion by viruses. J. Biosci. 35, 647-663 (2010). 
58. Linger, R. M. A., Keating, A. K., Earp, H. S. \& Graham, D. K. TAM Receptor Tyrosine Kinases: Biologic Functions, Signaling, and Potential Therapeutic Targeting in Human Cancer. in Advances in Cancer Research 100, 35-83 (Academic Press, 2008).

59. Monney, L. et al. Th1-specific cell surface protein Tim-3 regulates macrophage activation and severity of an autoimmune disease. Nature 415, 536 (2002).

60. Trajkovic, V., Sweet, M. J. \& Xu, D. T1/ST2-an IL-1 receptor-like modulator of immune responses. Cytokine Growth Factor Rev. 15, 87-95 (2004).

61. Shi, X. et al. Impact of HBV replication in peripheral blood mononuclear cell on HBV intrauterine transmission. Front. Med. (2017). doi:10.1007/s11684-017-0597-5

62. Wieland, S., Thimme, R., Purcell, R. H. \& Chisari, F. V. Genomic analysis of the host response to hepatitis B virus infection. Proc. Natl. Acad. Sci. U. S. A. 101, 6669-6674 (2004).

63. Doyle, T., Goujon, C. \& Malim, M. H. HIV-1 and interferons: who's interfering with whom? Nat. Rev. Microbiol. 13, 403-413 (2015).

64. Heim, M. H. \& Thimme, R. Innate and adaptive immune responses in HCV infections. J. Hepatol. 61, S14-25 (2014).

65. Fletcher, S. P. et al. Transcriptomic analysis of the woodchuck model of chronic hepatitis B. Hepatol. Baltim. Md 56, 820-830 (2012).

66. Stacey, A. R. et al. Induction of a striking systemic cytokine cascade prior to peak viremia in acute human immunodeficiency virus type 1 infection, in contrast to more modest and delayed responses in acute hepatitis B and C virus infections. J. Virol. 83, 3719-3733 (2009).

67. Mutz, P. et al. HBV Bypasses the Innate Immune Response and Does not Protect HCV From Antiviral Activity of Interferon. Gastroenterology (2018). doi:10.1053/j.gastro.2018.01.044

68. Wieland, S. F. \& Chisari, F. V. Stealth and Cunning: Hepatitis B and Hepatitis C Viruses. J. Virol. 79, 9369-9380 (2005).

69. van Montfoort, N. et al. Hepatitis B Virus Surface Antigen Activates Myeloid Dendritic Cells via a Soluble CD14-Dependent Mechanism. J. Virol. 90, 6187-6199 (2016). 
70. Cheng, X. et al. Hepatitis B virus evades innate immunity of hepatocytes but activates cytokine production by macrophages. Hepatol. Baltim. Md 66, 1779-1793 (2017).

71. Park, B. S. \& Lee, J.-O. Recognition of lipopolysaccharide pattern by TLR4 complexes. Exp. Mol. Med. 45, e66 (2013).

72. Kim, J. H. et al. Systemic Armed Oncolytic and Immunologic Therapy for Cancer with JX-594, a Targeted Poxvirus Expressing GM-CSF. Mol. Ther. 14, 361-370 (2006).

73. Mastrangelo, M. J. et al. Intratumoral recombinant GM-CSF-encoding virus as gene therapy in patients with cutaneous melanoma. Cancer Gene Ther. 6, 409 (1999).

74. Liu, P.-S. et al. $\alpha$-ketoglutarate orchestrates macrophage activation through metabolic and epigenetic reprogramming. Nat. Immunol. 18, 985-994 (2017).

75. Demento, S. L. et al. Inflammasome-activating nanoparticles as modular systems for optimizing vaccine efficacy. Vaccine 27, 3013-3021 (2009). 
Figure 1: An HBV protein co-localized with liver $M \Phi$ and the proportion of antiinflammatory $M \Phi$ is higher in CHB liver biopsies. HBc (HBV capsid protein), CD68 (total macrophage) and/or CD163 (M2 macrophage), in liver biopsies from non-infected or HBVinfected patients (Table S1), were stained by immune-histo-chemistry (IHC). (A,B) Representative photos of $\mathrm{HBc}$ (brown arrows) and CD68 (pink arrows) stainings. (C) Representative photos of CD163 stainings. $(A, B, C)$ Bars represent $50 \mu \mathrm{m}$. (D) Quantification of CD163 stainings. Horizontal bars represent the median of values and data were submitted to Kruskal Wallis test. ns = not significant. $(E)$ Correlation curve between CD163 and HBc stainings.

Figure 2: Levels of pro-inflammatory markers decreased in liver $M \Phi$ exposed to HBV. $(A, B)$ Total LMNC were isolated from liver resection and exposed or not to HBV for $24 \mathrm{~h}$. (C,D,E) Liver MФ were isolated from liver resection, exposed or not to HBV for $24 \mathrm{~h}$ and stimulated $24 \mathrm{~h}$ later with (C,D) $100 \mathrm{ng} / \mathrm{mL}$ of LPS (TLR4-L) or (C,E) $100 \mathrm{ng} / \mathrm{mL}$ of LPS +100 $\mathrm{ng} / \mathrm{mL}$ of Poly (dA:dT) (AIM2-L) for another $24 \mathrm{~h}$. (A-E) Supernatant were collected and the levels of IL-1 $\beta$ and IL-10 were assessed by ELISA. Data are presented either as nonnormalised secretion or as ratio to non-exposed cells. Results are the median of five independent experiments (with five different donors) each performed with three biological replicates. Horizontal bars represent the median and data were submitted to Wilcoxon test. ns $=$ not significant.

Figure 3: HBV interferes with M1-MDM differentiation. Monocytes were purified from peripheral blood mononuclear cells, differentiated into (B-F) M1-MDM (upon GM-CSF culture) or (B-E,G) M2-MDM (upon M-CSF culture) in the presence or not of HBV before stimulation with $10 \mathrm{ng} / \mathrm{mL}$ of LPS for 3 hours. (A) Schematic representation of the experiment. Medium 
change is indicated by dotted arrows. (B-G) Levels of the indicated secreted cytokines were assessed by ELISA and analysed either as non-normalised secretion or as ratio to nonexposed cells. Results are the mean of six independent experiments (with six different donors) each performed with three biological replicates. Horizontal bars represent the median and data were submitted to Wilcoxon test. ns = not significant.

Figure 4: HBV increases M2-MDM activation. Monocytes were purified from peripheral blood mononuclear cells, differentiated into (B) M1-MDM (upon GM-CSF culture) or (C) M2-MDM (upon M-CSF culture) and stimulated with $10 \mathrm{ng} / \mathrm{mL}$ of LPS for 3 hours in the presence or not of HBV. (A) Schematic representation of the experiment. Medium change is indicated by dotted arrows. (B-C) Levels of the indicated secreted cytokines were assessed by ELISA and analysed as ratio to non-exposed cells. Results are the mean of six independent experiments (with six different donors) each performed with three biological replicates. Horizontal bars represent the median and data were submitted to Wilcoxon test. ns = not significant.

\section{Figure 5: HBV effect on macrophages is dependant of virus proteins quantity but} independent of viral entry and replication. (A-D) Monocytes were purified from peripheral blood mononuclear cells, then differentiated into M1-MDM (upon GM-CSF culture; panels A and D) or M2-MDM (upon M-CSF culture; panels B and C) and stimulated with $10 \mathrm{ng} / \mathrm{mL}$ of LPS for 3 hours. Cells were exposed or not to HBV, Cytochalasin D, AAV-GFP or AAV-HBV during their differentiation and activation $(A, D)$, or their activation $(B, C)$. (A-D) Levels of the indicated secreted cytokines were assessed by ELISA and analysed as ratio to non-exposed cells (A-B: MOI 0; C: Mock; D: HBV-). Results are the mean of two to five independent experiments (with two or five different donors) each performed with three biological replicates. Horizontal bars represent the median and data were submitted to Wilcoxon test. ns $=$ not significant. 
Figure 6: HBV-producing cells impair M1-MDM differentiation and enhance M2-MDM activation. Monocytes were purified from peripheral blood mononuclear cells, differentiated into (B) M1-MDM (upon GM-CSF culture) or (C) M2-MDM (upon M-CSF culture) and stimulated with $10 \mathrm{ng} / \mathrm{mL}$ of LPS for 3 hours, in the presence of non-infected HepG2-NTCP (HBV- cells) or HepAD38 (HBV+ cells) during their differentiation or activation, respectively.

(A) Schematic representation of the experiment. Medium change is indicated by dotted arrows.

$(B, C)$ Levels of the indicated secreted cytokines were assessed by ELISA and analysed as ratio to cells exposed to HBV-cells. Results are the median of five independent experiments (with five different donors) each performed with three biological replicates. Horizontal bars represent the median and data were submitted to Wilcoxon test. ns $=$ not significant.

Figure 7: HBV induces further immunosuppressive properties to M2-MDM. Lymphocytes

782

783

784

785 were purified from peripheral blood mononuclear cells and exposed to media (mock) or LPSstimulated M2-MDM in the absence (no-HBV M2-MDM) or presence (HBV stim M2-MDM) of HBV during their stimulation (CM; conditioned medium) for $2 \mathrm{~h}$ before stimulation with $20 \mathrm{ng} / \mathrm{mL}$ of PMA and $500 \mathrm{ng} / \mathrm{mL}$ of ionomycine. Supernatants were collected $22 \mathrm{~h}$ later and the levels of TNF- $\alpha$ assessed by ELISA. Results, presented as ratio to non-treated cells (mock), are the mean +/- standard deviation of three independent experiments (lymphocytes from three different donors) each performed with three biological replicates. Data were submitted to Wilcoxon test. ns= not significant.

Figure 8: IL-1ß strongly inhibits establishment of HBV infection in hepatocytes. (A) dHepaRG cells or (B) PHH were treated with $1 \mathrm{ng} / \mathrm{mL}$ of recombinant $\mathrm{IL}-1 \beta$ or $20 \mathrm{ng} / \mathrm{mL}$ of recombinant IL-10, 24h before and during the infection with HBV. Seven days post infection, supernatants were collected and levels of HBeAg and HBsAg quantified by ELISA. Cells were 
harvested, total RNA or DNA extracted, and levels of HBV RNAs and cccDNA quantified by RT-qPCR or qPCR analysis. Cell viability was assessed by neutral red uptake assay. Results, presented as ratio to non-treated cells, are the mean +/- standard deviation of three independent experiments (three batches of dHepaRG cells and three donors of PHH) each performed with three biological replicates. Data were submitted to Wilcoxon test.

\section{Figure 9: HBV prevents the antiviral effect of M1-MDM on HBV establishment. dHepaRG} cells were treated $24 \mathrm{~h}$ before and during HBV infection with concentrated supernatants from LPS-stimulated M1-MDM (CM: conditioned medium pooled from at least five independent experiment) exposed to HBV during their differentiation or during their stimulation. Seven days post infection, supernatants were collected and levels of HBeAg and HBsAg quantified by ELISA. Cells were harvested, total DNA extracted and levels of cccDNA quantified by specific qPCR analysis. Cell viability was assessed by neutral red uptake assay. Results, presented as ratio to non-treated cells (mock), are the mean $+/$ - standard deviation of three independent experiments each performed with three biological replicates. Data were submitted to Wilcoxon test. ns= not significant. 
A. LMNC

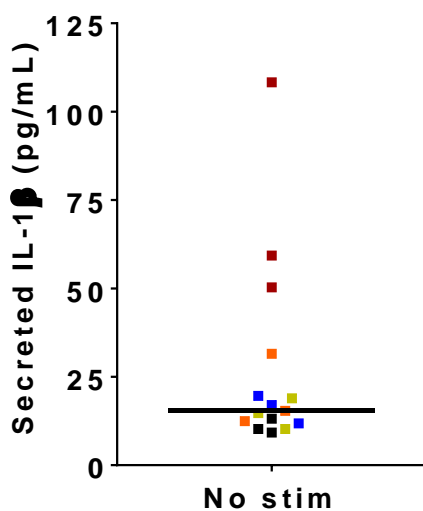

C. Liver-MФ

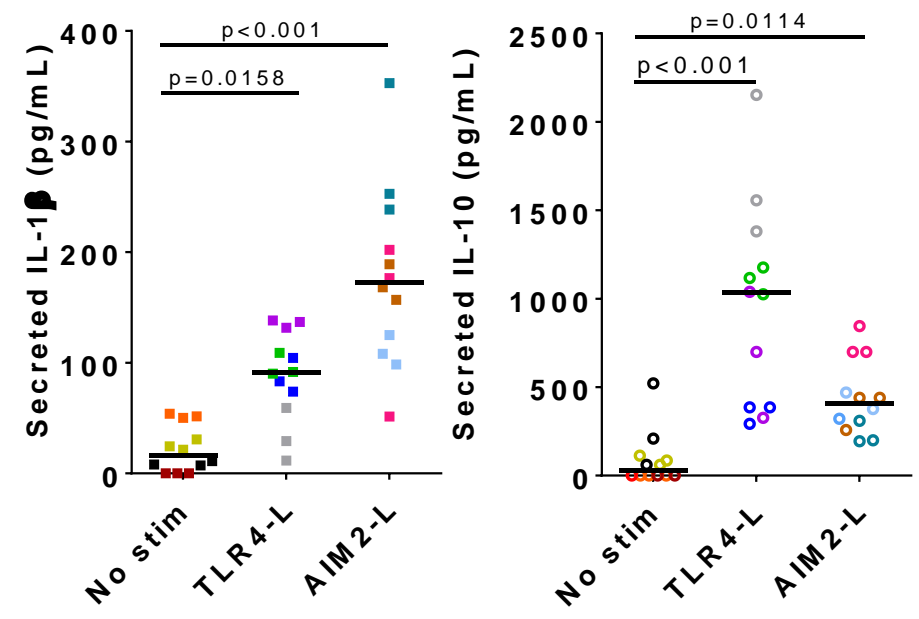

E. (Poly (dA:dT) + LPS)-stimulated-Liver MФ

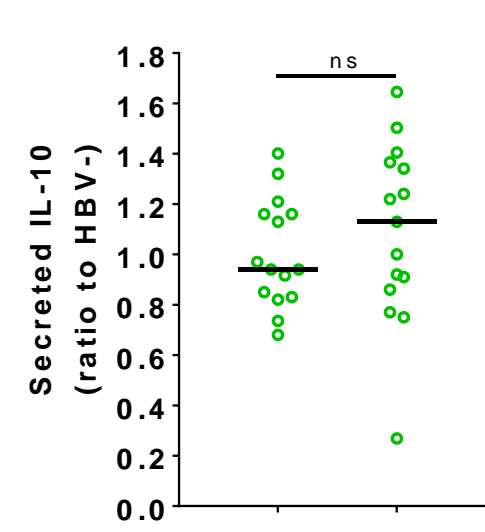

HB V:
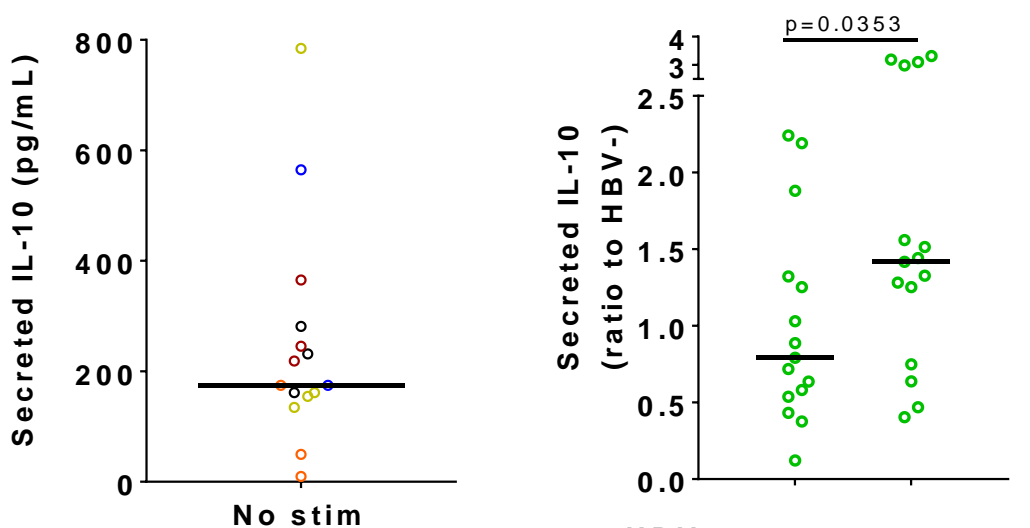

HBV : - +

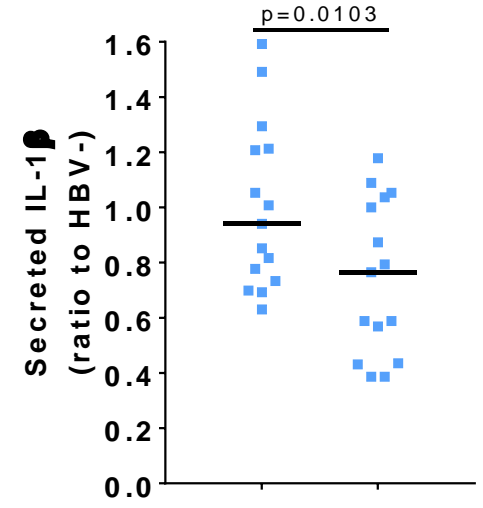

HBV : - $\quad+$

D. LPS-stimulated-Liver MФ
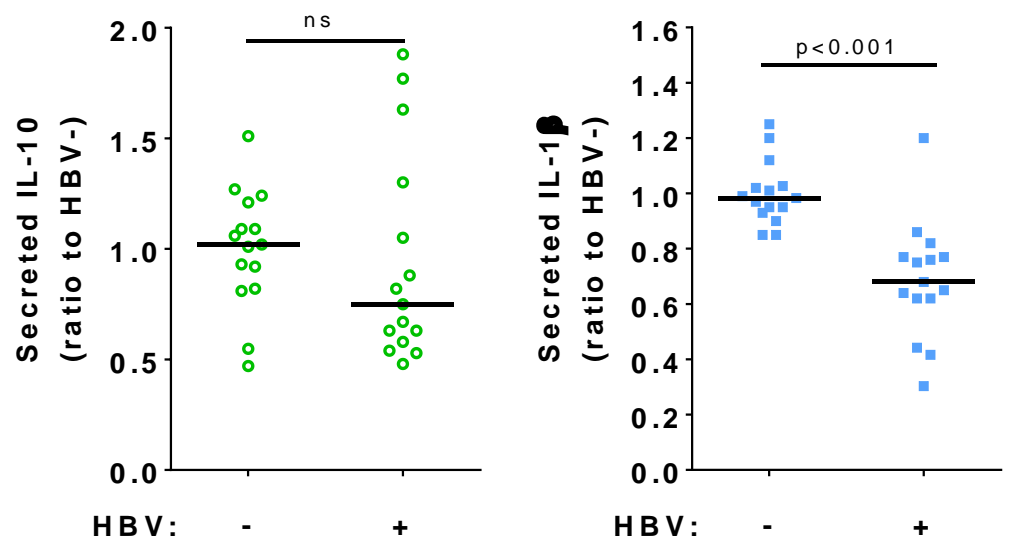


\section{A.}

HBV wash medium exchange

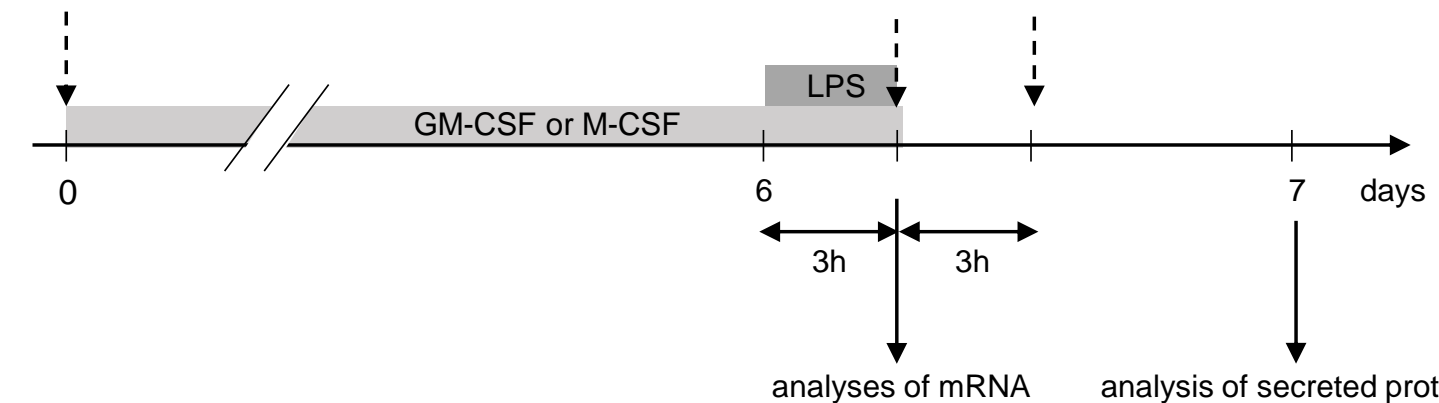

B.

C.

D.

E.

\section{IL-6}

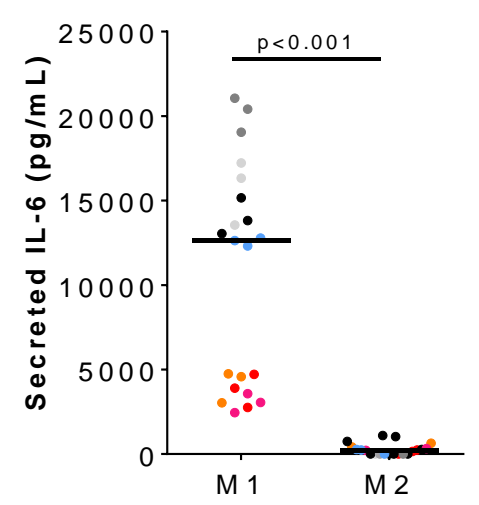

F. M1-MDM (secretion)

$$
\text { IL - } 6
$$

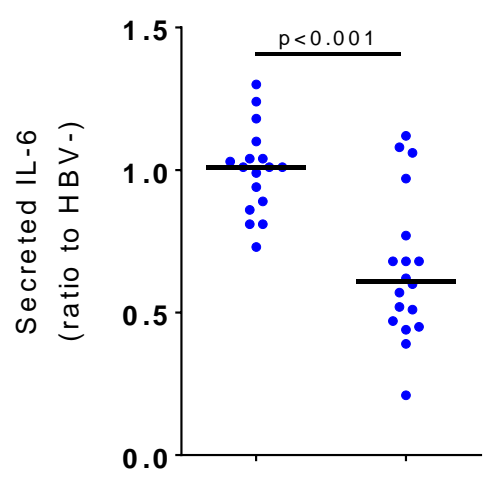

HBV :
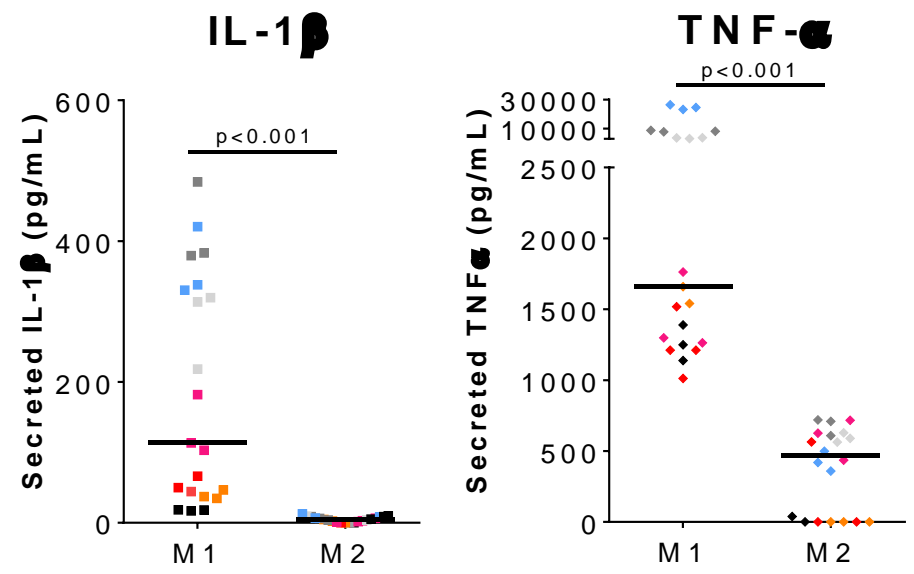

G. M2-MDM (secretion)

IL -10

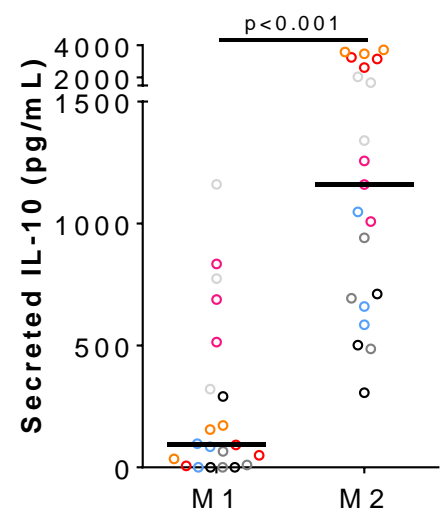

IL - 10

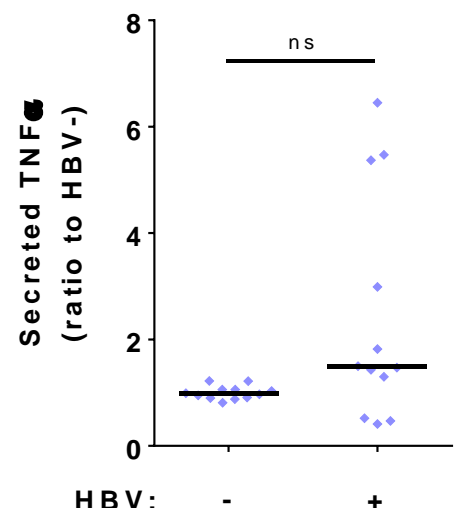

IL - 1 P

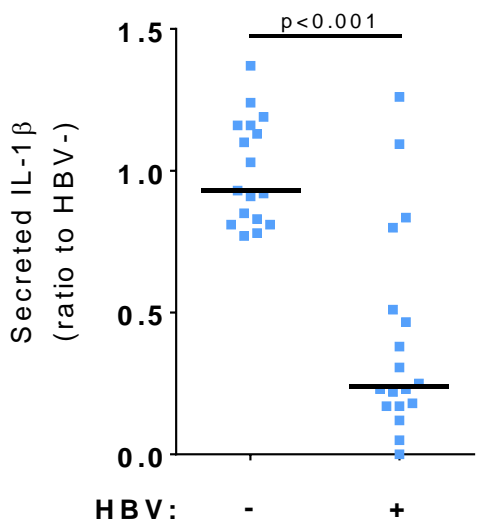

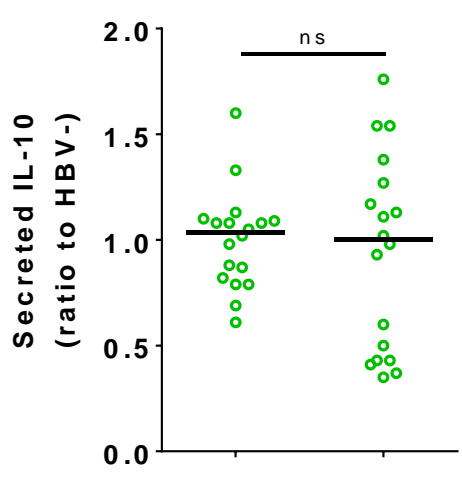

HBV: - + 
A.

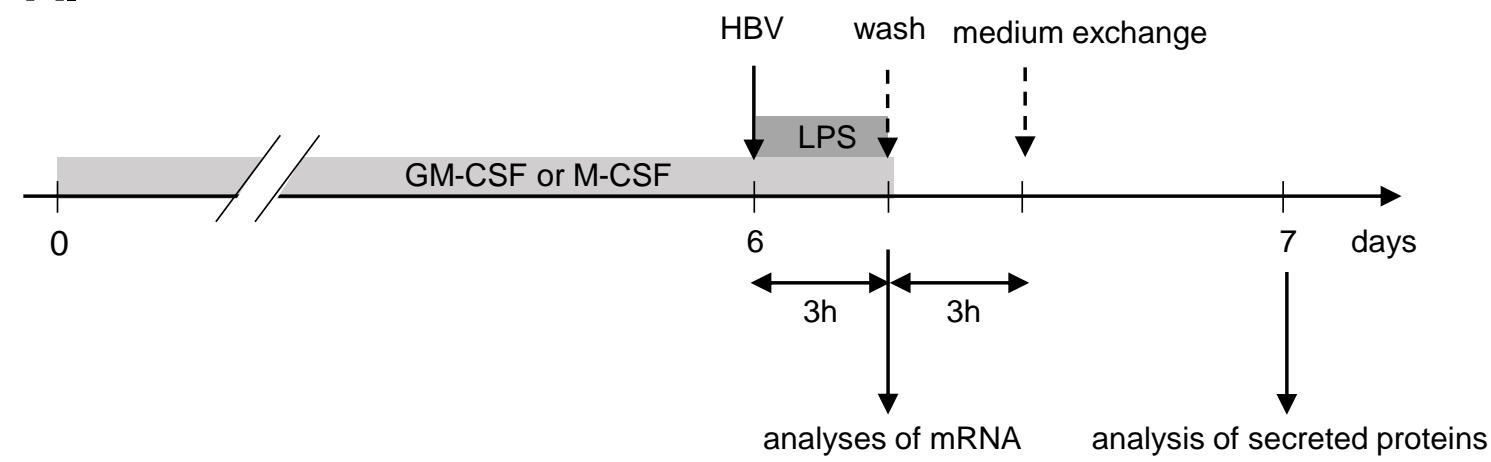

B. M1-MDM (secretion)

C. M2-MDM (secretion)

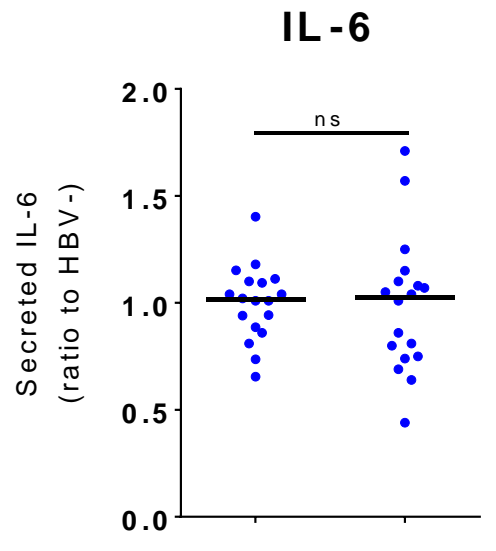

HBV :
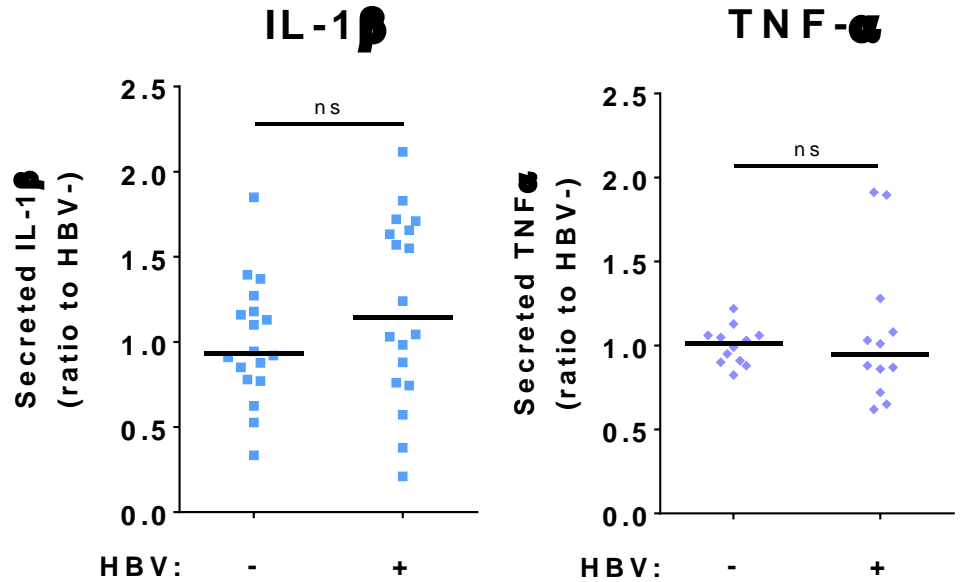

IL - 10

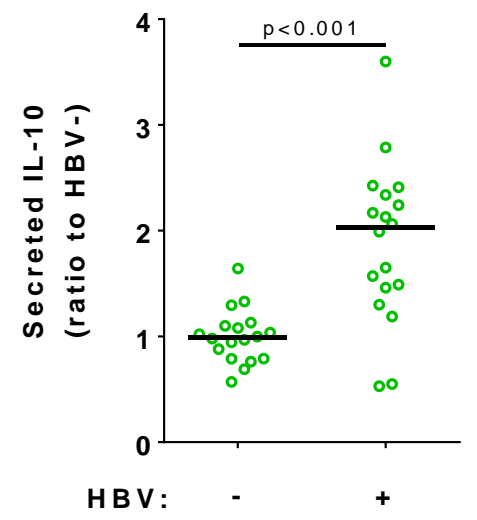


A. M1-MDM

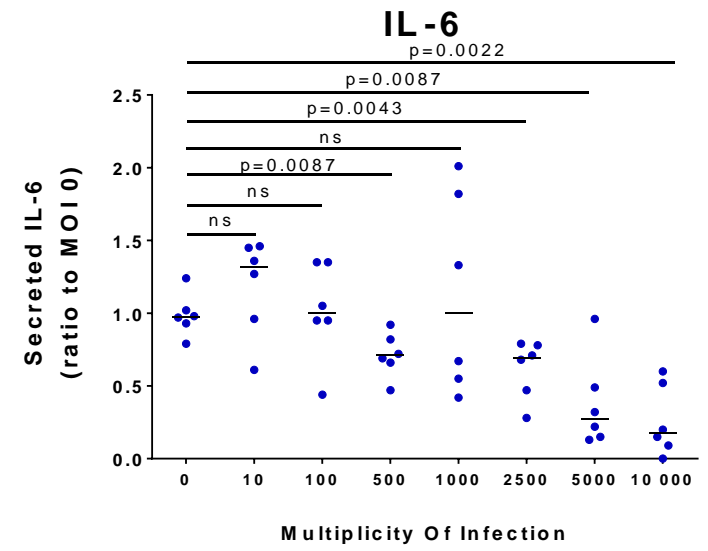

\section{M1-MDM}

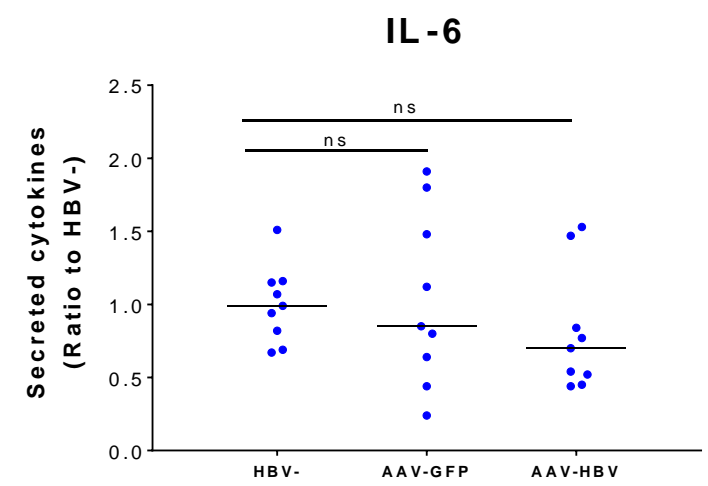

C. M2-MDM
IL - 10

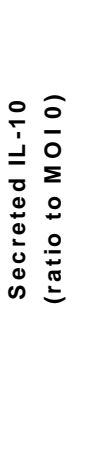

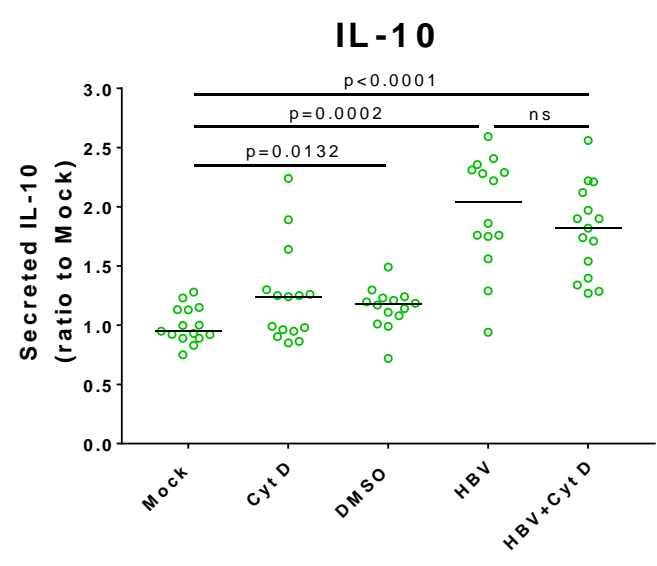

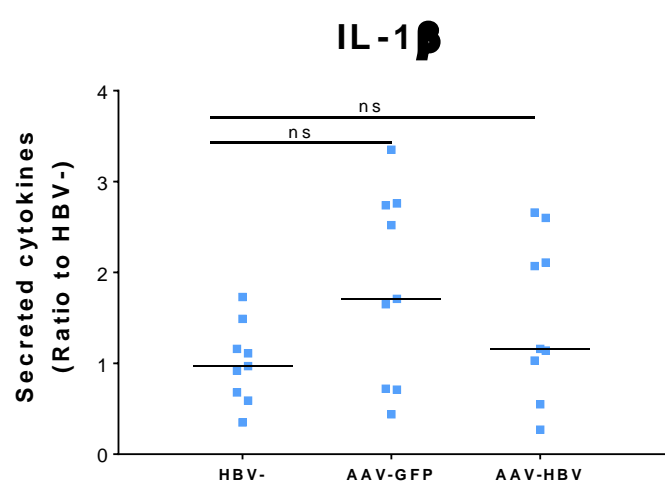

T N F -

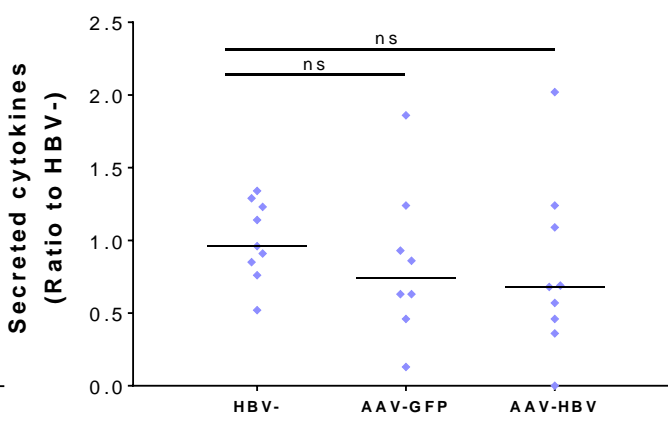


A. wash medium exchange
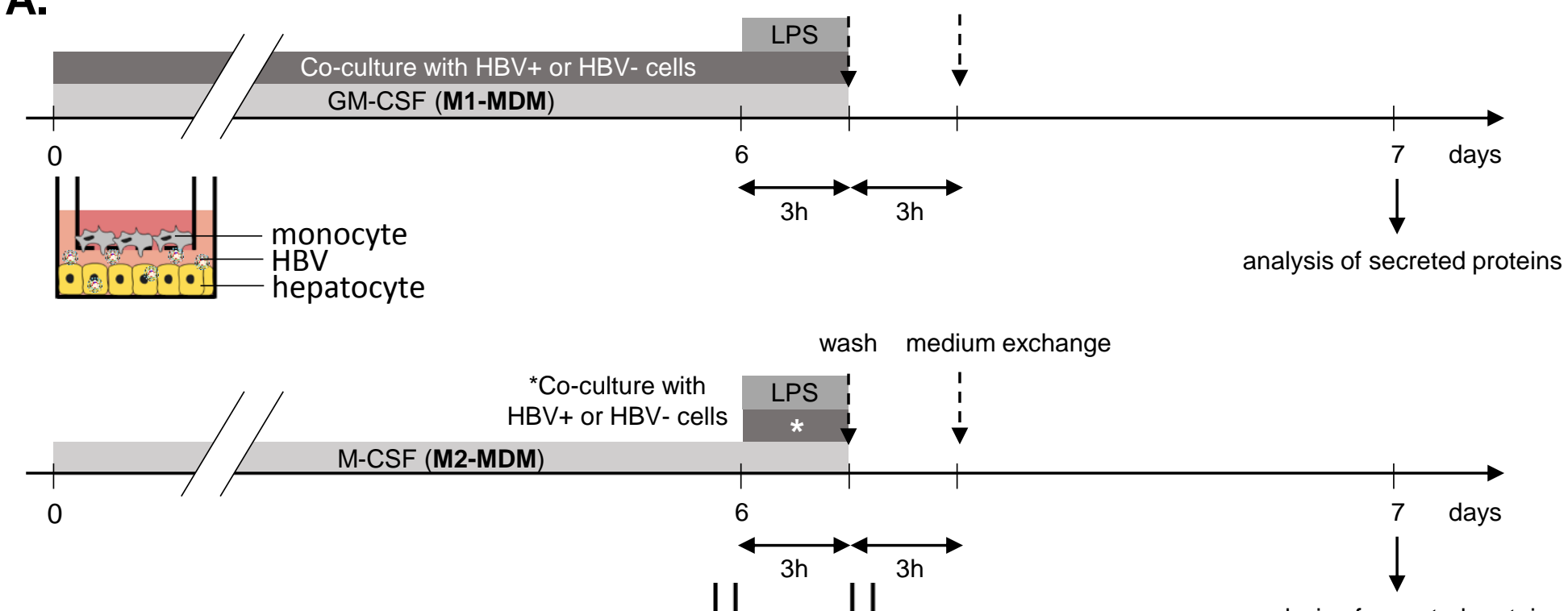

analysis of secreted proteins

C. M2-MDM

B. M1-MDM

T N F -

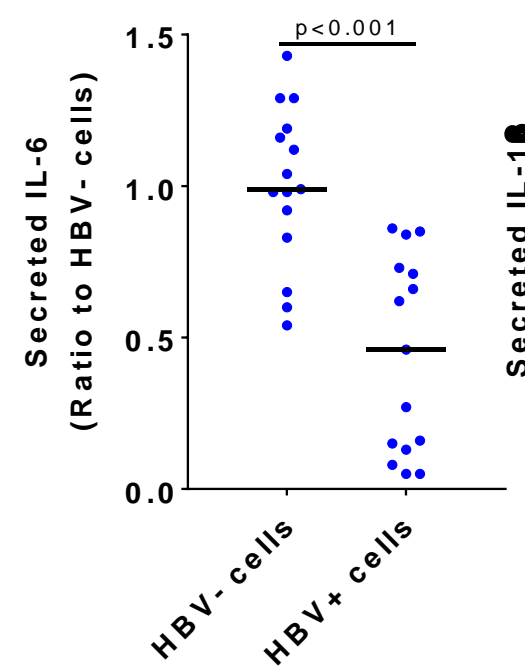

IL - 1

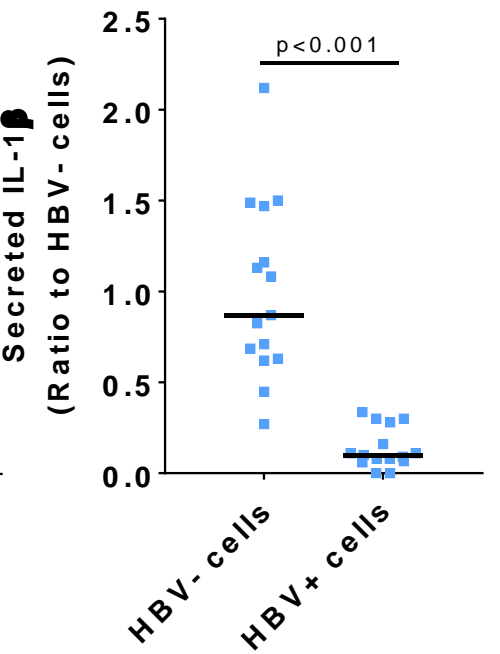

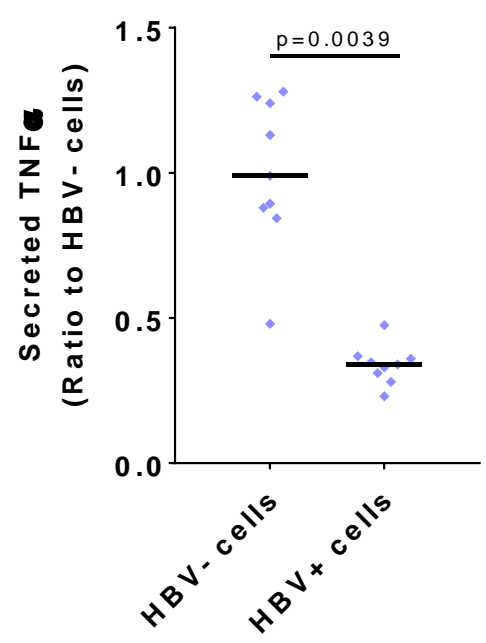

IL - 10

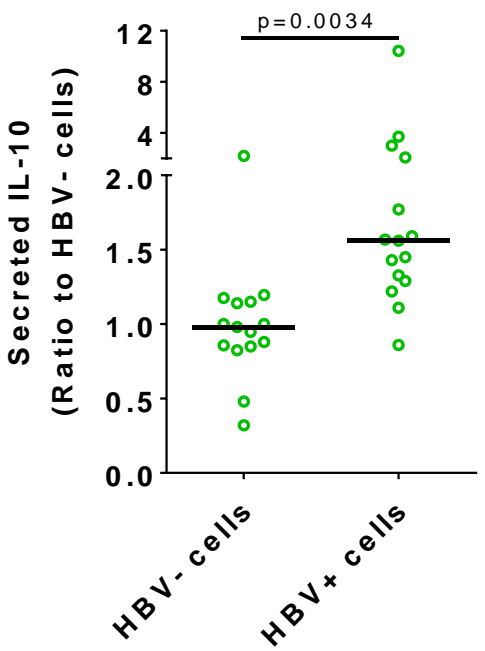

\section{Figure 6}


lymphocytes

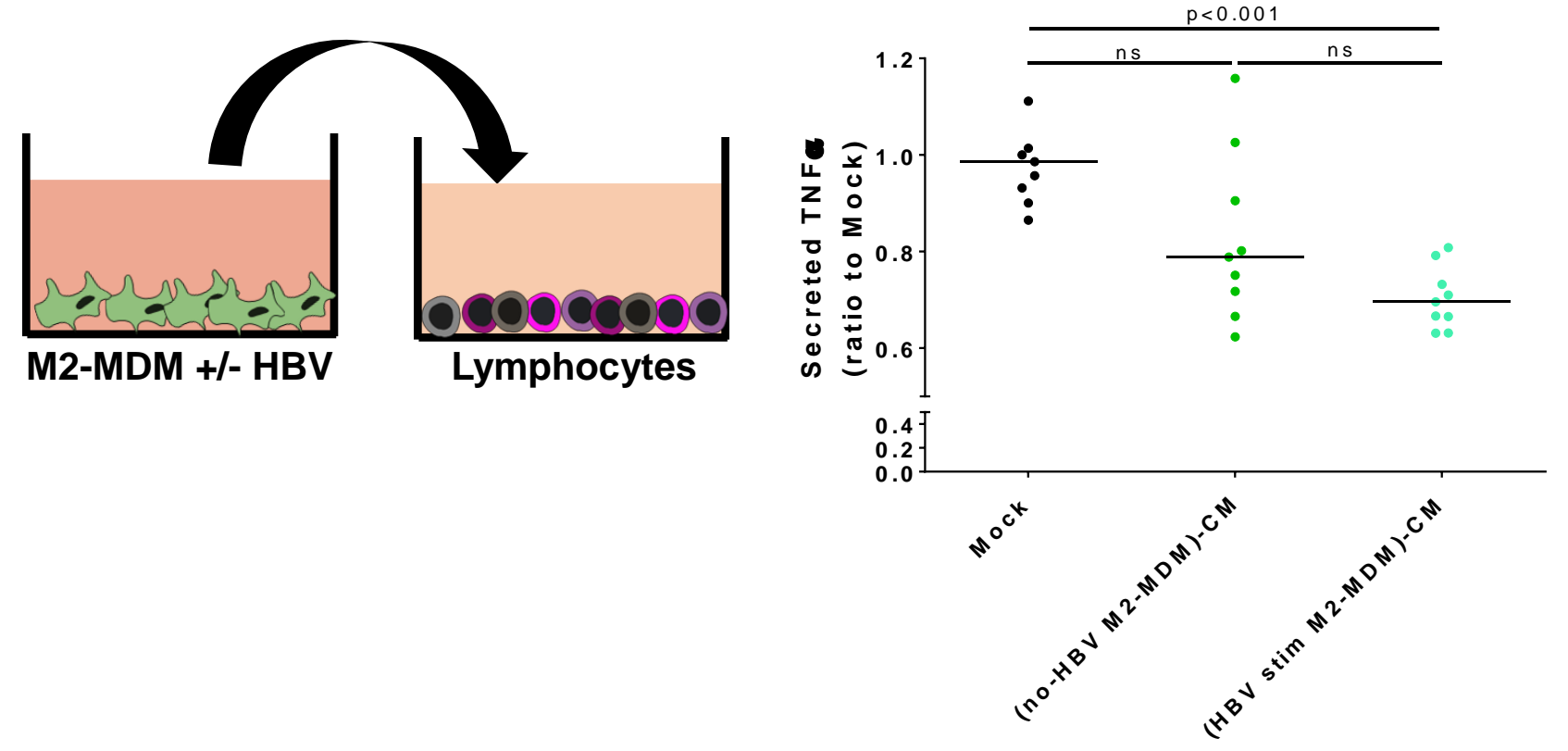

\section{Figure 7}


A.

dHepaRG

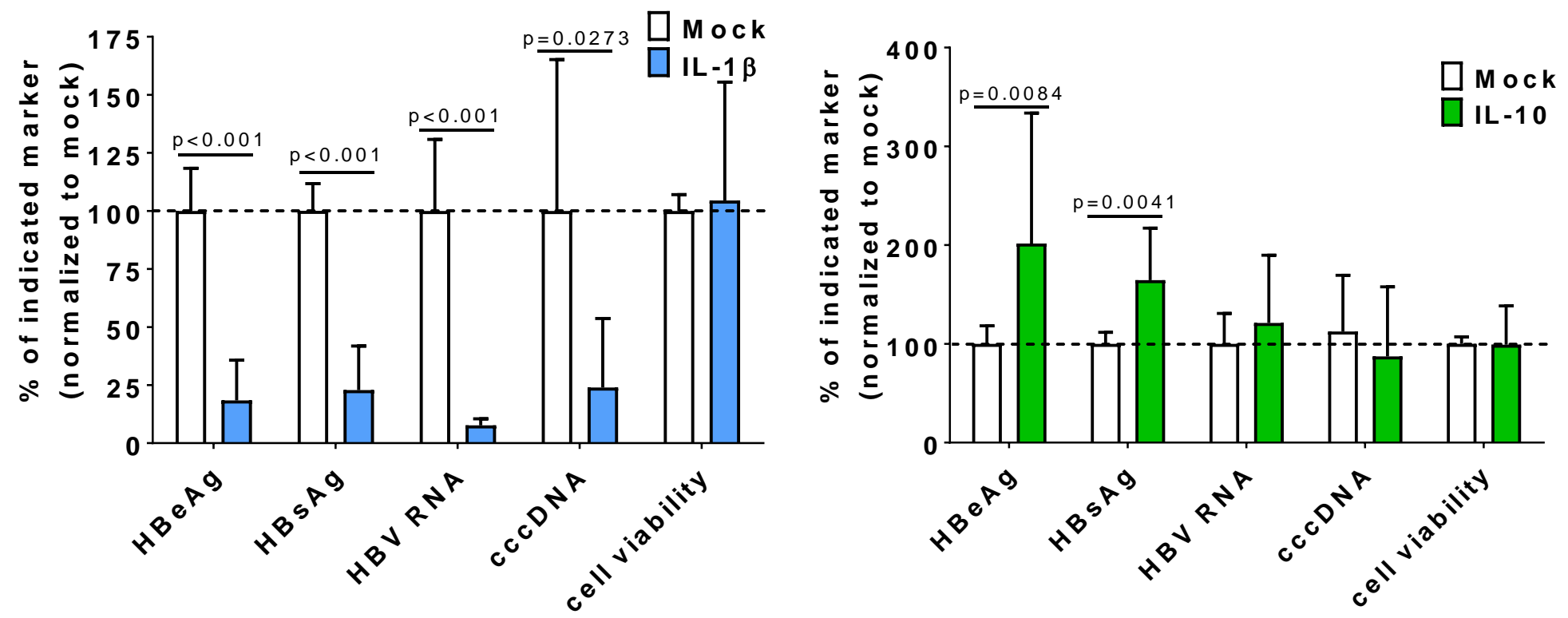

B.

PHH
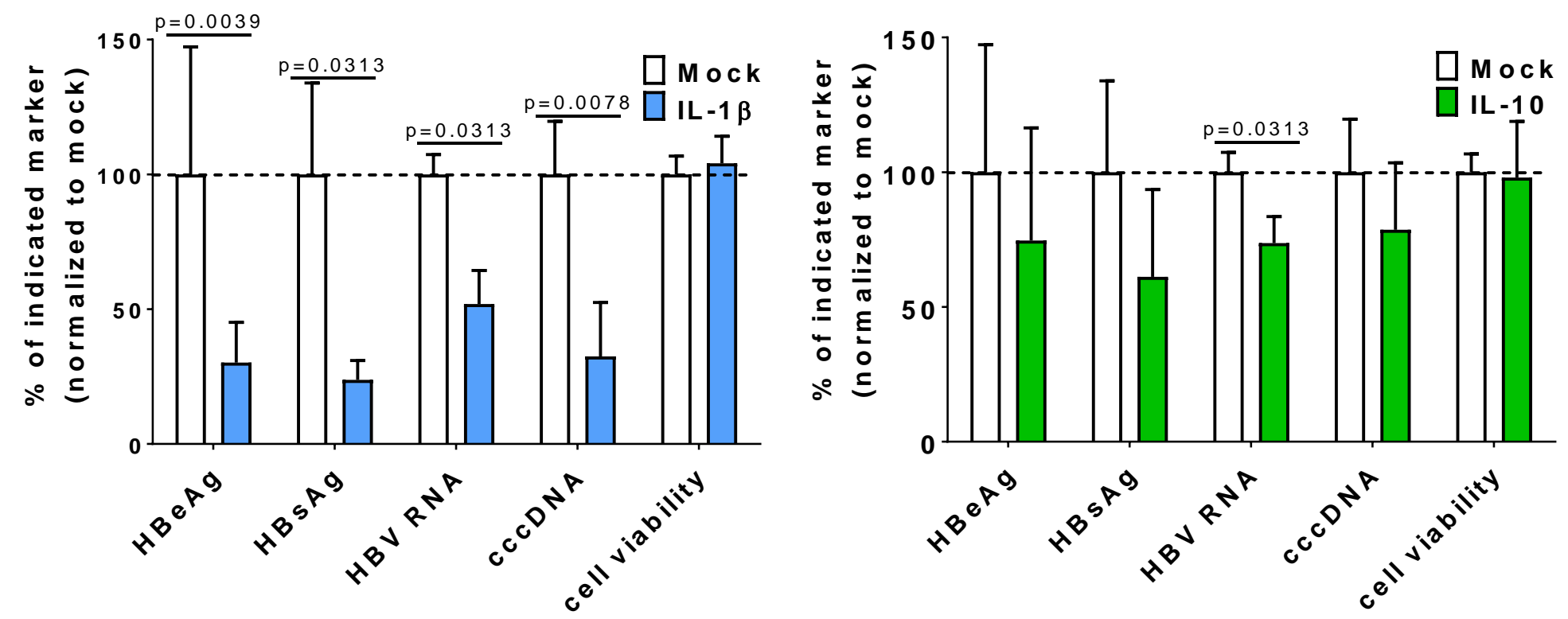


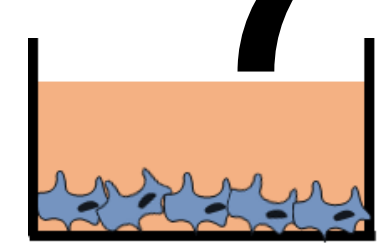

M1-MDM +/- HBV

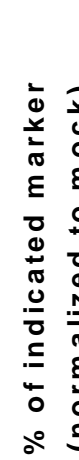
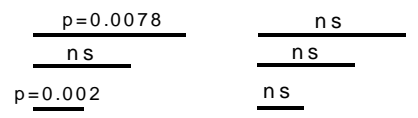

$\square$ M ock

(no-HB V M 1-M D M)-C M

$\square($ HBV diff M 1-M DM)-CM

$\square($ H B stim M 1-M DM)-CM

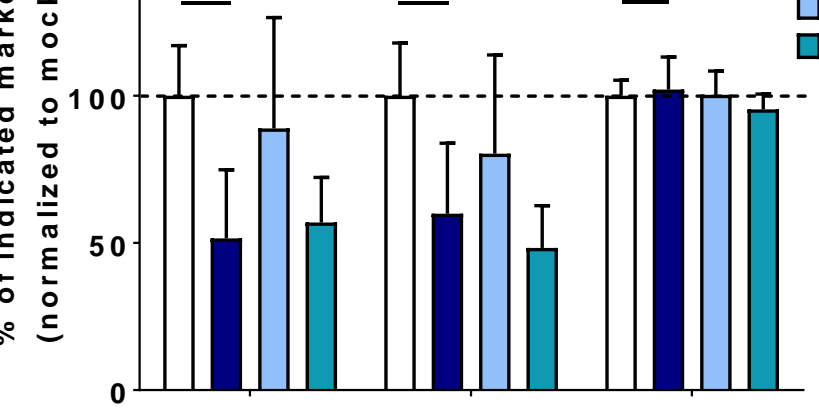
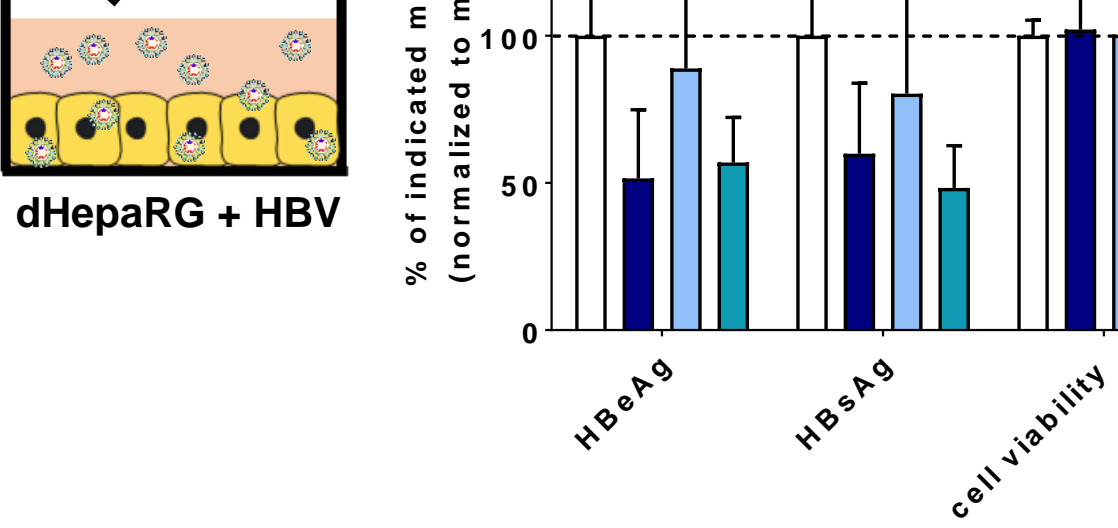

\section{Figure 9}


A. control mouse control mouse

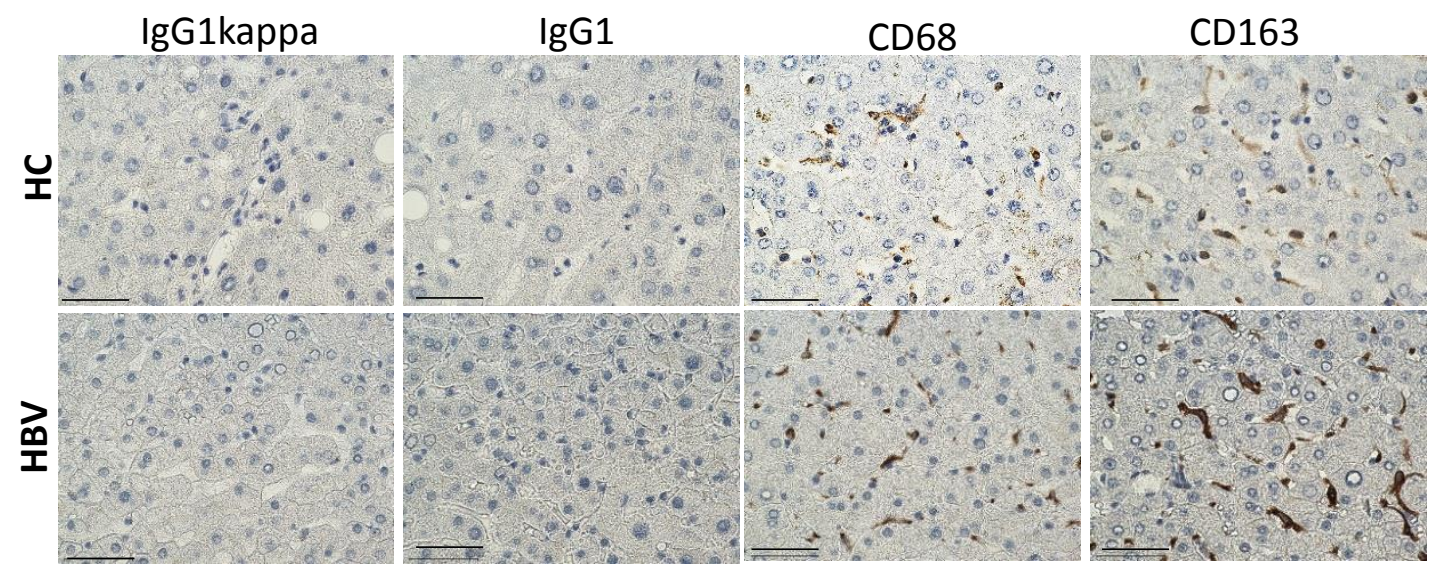

B.

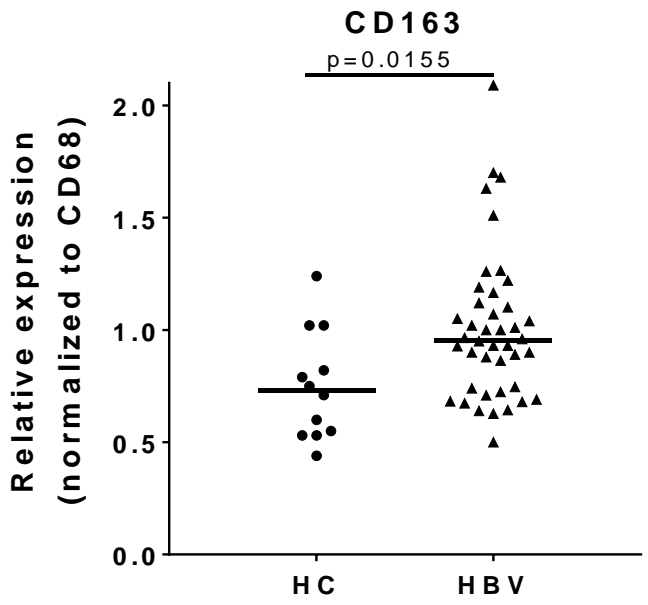

Supplementary figure 1: The levels of anti-inflammatory macrophages are higher in liver biopsies from HBV infected patients (French cohort). (A,B) Liver biopsies from healthy controls (HC), and HBV positive (HBV) patients were stained with control or target specific antibodies. Representative photos of the stainings are shown. The black bars represent $50 \mu \mathrm{m}$. (B) The levels of positive CD163 signals were quantified compared to the levels of positive CD68 signals. Horizontal bars represent the median of values and data were submitted to Kruskal Wallis test. 


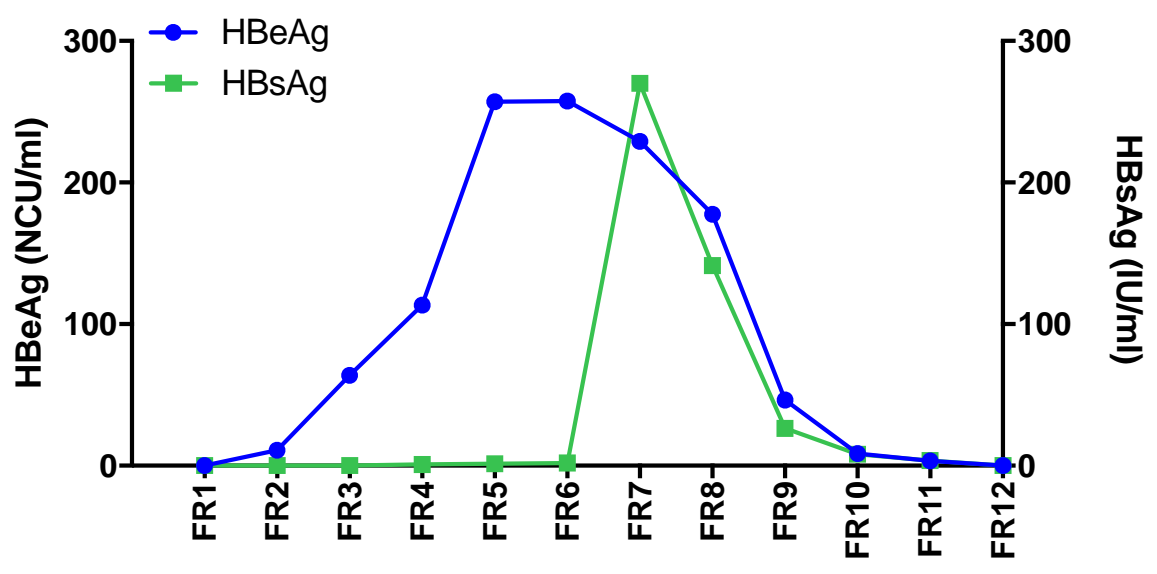

HBV-DNA

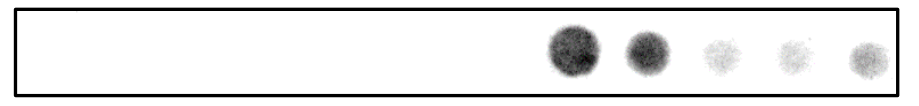

$\mathrm{HBC}$

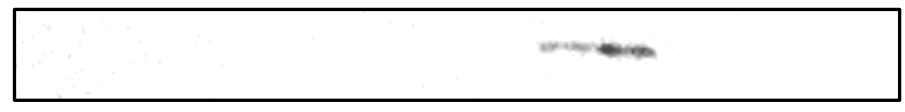

Supplementary figure 2: Representative characterization of HBV inoculum. Supernatants from HepAD38 were concentrated by ultracentrifugation and characterized by analysis of the fractions from a 5.6$56 \%$ iodixanol gradient. Viral parameters were assessed in each fractions by ELISA (HBeAg and HBsAg), dot blot (HBV DNA), and western-blot $(\mathrm{HBC})$ analyses. Representative characterization of one of the three HBV inoculums used for this study. 

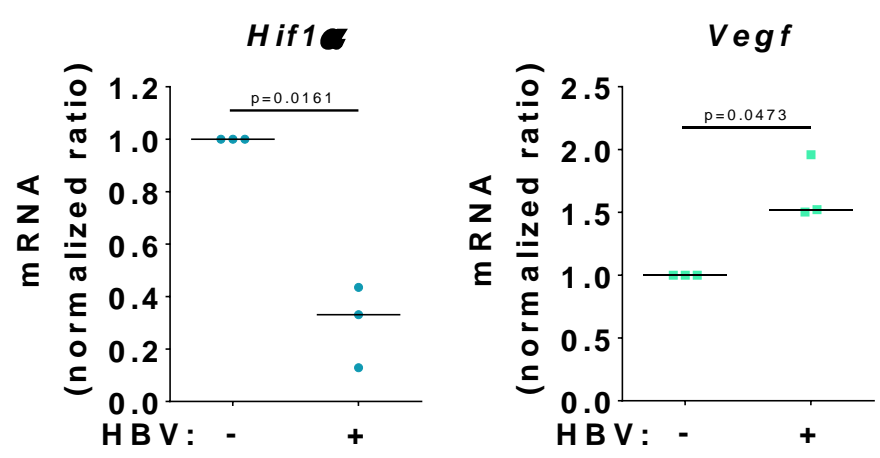

Supplementary figure 3: Levels of HIF1a and VEGF mRNAs in liver MФ exposed to HBV. Liver MФ were isolated, exposed or not to HBV for $24 \mathrm{~h}$ before stimulation with $100 \mathrm{ng} / \mathrm{ml}$ of LPS for $3 \mathrm{~h}$. Cells were harvested, total RNA were extracted and the levels of the indicated mRNA were assessed by RT-qPCR Results represent the mean of three independent experiments (three different donors). Horizontal bars represent the median and data were submitted to Mann Whitney test. 


\section{A. MDM exposed to HBV during their differentiation}
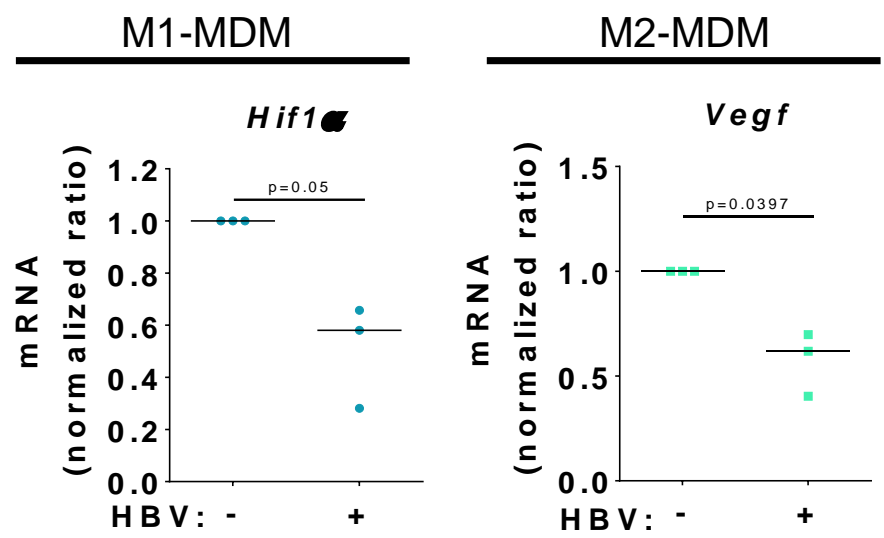

\section{B. MDM exposed to HBV during their activation}
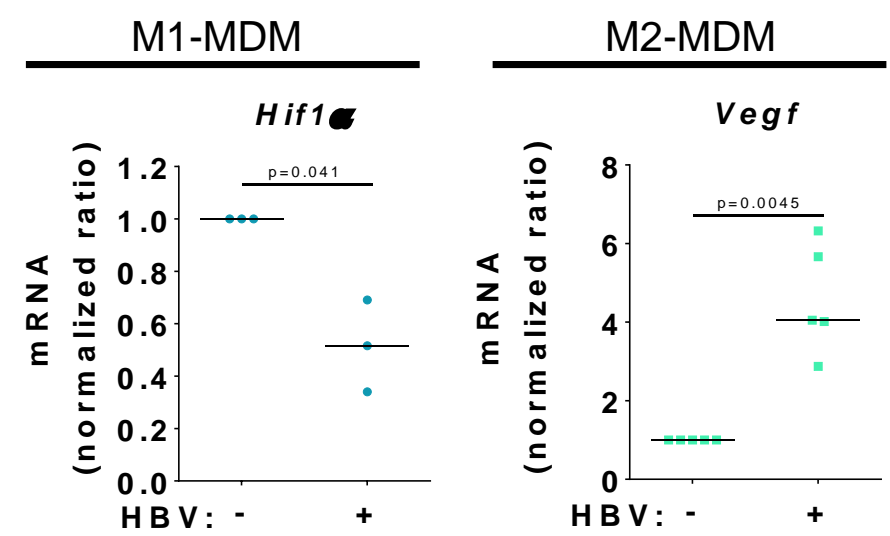

Supplementary figure 4: Levels of HIF1a and VEGF mRNAs in MDM exposed to HBV. (A-B) Monocytes were purified from peripheral blood mononuclear cells, differentiated into M1-MDM (upon GM-CSF culture) or M2-MDM (upon M-CSF culture) in the presence or not of HBV (A) during differentiation and activation or (B) during stimulation with $10 \mathrm{ng} / \mathrm{ml}$ of LPS for 3 hours. (A, B) Cells were harvested, total RNA were extracted and the levels of the indicated mRNA were assessed by RT-qPCR. Results represent the mean of three independent experiments (three different donors). Horizontal bars represent the median and data were submitted to Mann Whitney test. 
A.

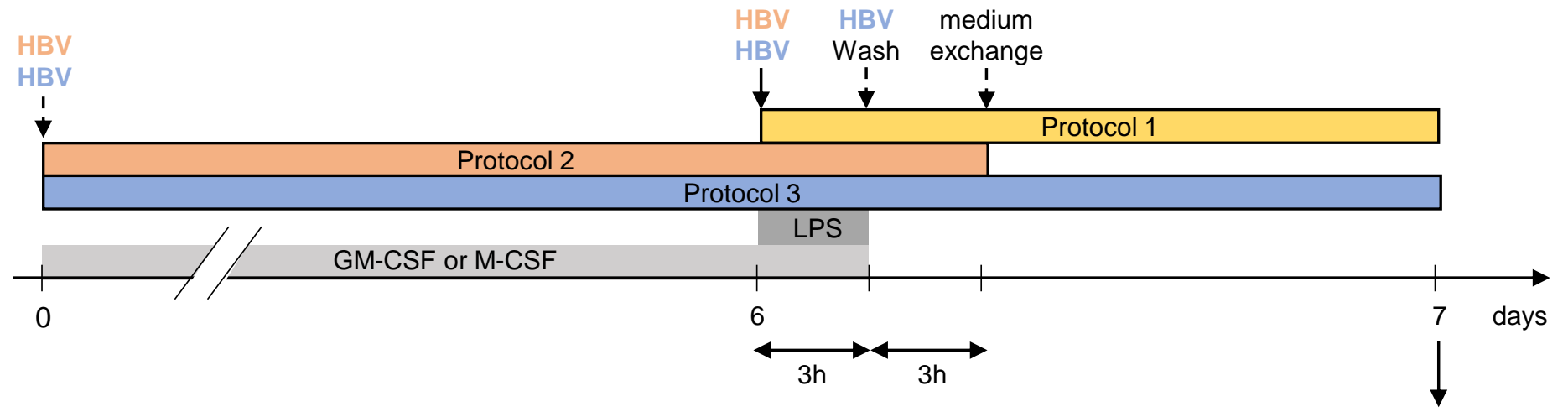

analysis of secreted proteins

B. M1-MDM and M2-MDM exposed to HBV according to protocol 1

M1-MDM

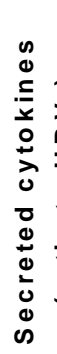

IL -6

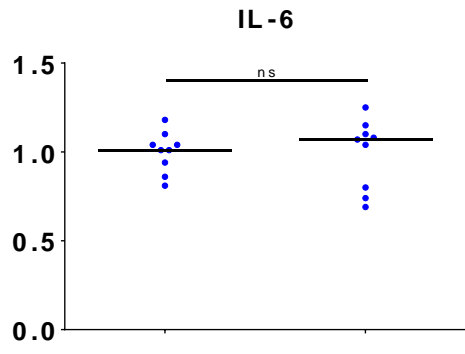

H B V :
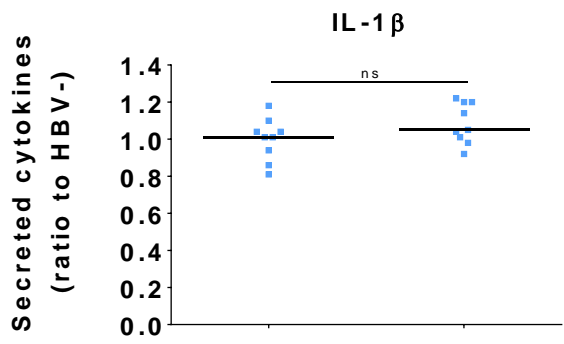

HB V :
M2-MDM

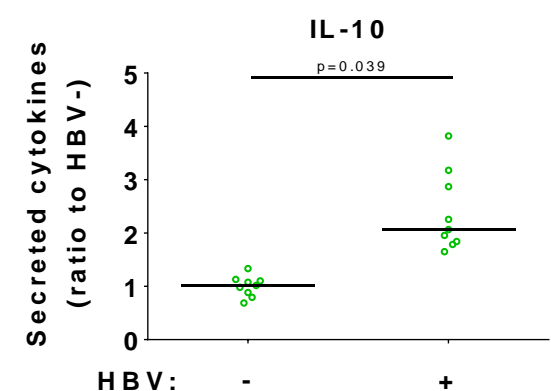

C. M1-MDM and M2-MDM exposed to HBV according to protocol 2

M1-MDM

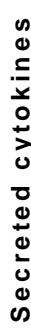

0
0
1
$x$
0
2
0
0
0
0
0
0
0
0
0

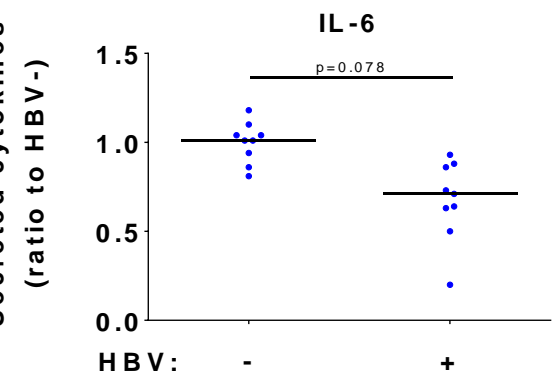

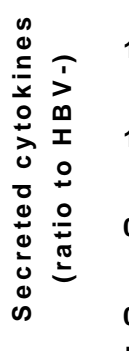

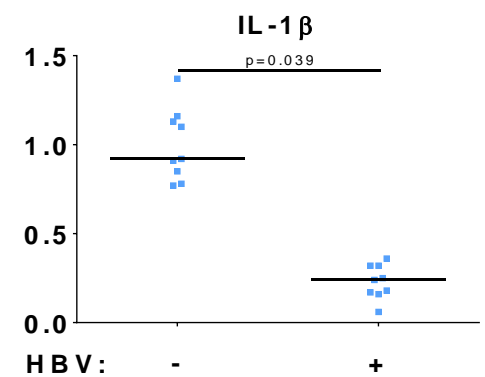

M2-MDM

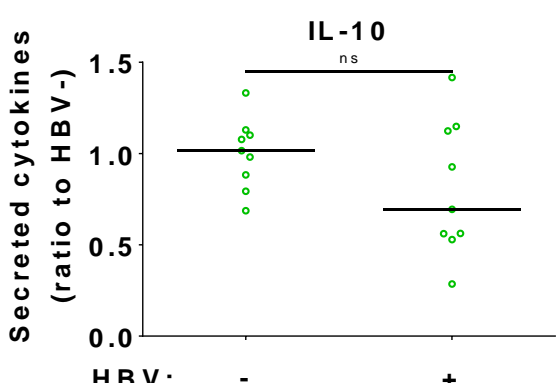

D. M1-MDM and M2-MDM exposed to HBV according to protocol 3

M1-MDM
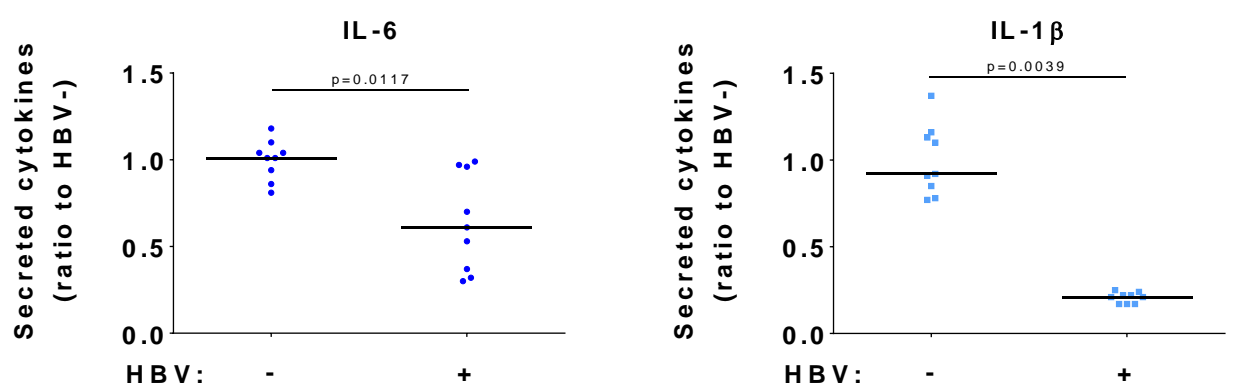

Supplementary figure 5: HBV interfere with M1-MDM differentiation and increase M2-MDM activation. Monocytes were purified from peripheral blood mononuclear cells, differentiated into M1-MDM (upon GMCSF culture) or M2-MDM (upon M-CSF culture) and stimulated with $10 \mathrm{ng} / \mathrm{ml}$ of LPS for 3 hours, and HBV was added at different time points. (A) Schematic representation of the experiment. Media removals are indicated by dotted arrows. (B-D) Levels of the indicated secreted cytokines were assessed by ELISA and analysed as ratio to non-exposed cells. Results are the mean of three independent experiments (with three different donors) each performed with three biological replicates. Horizontal bars represent the median and data were submitted to Wilcoxon test. 
A. Liver $М \Phi$

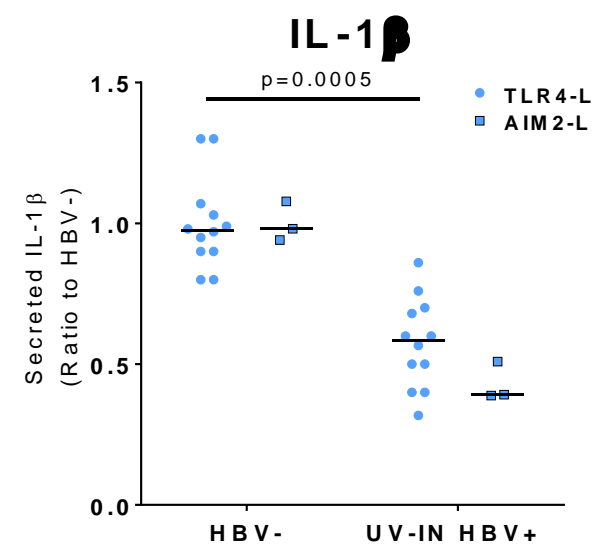

C. M1-MDM

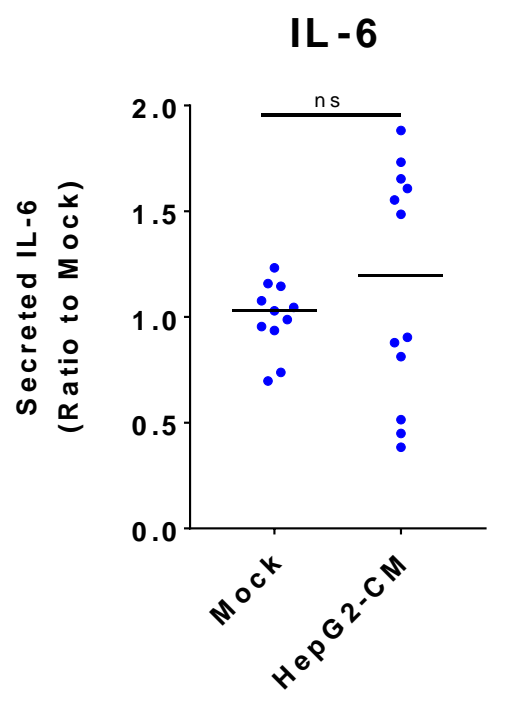

B. M1-MDM
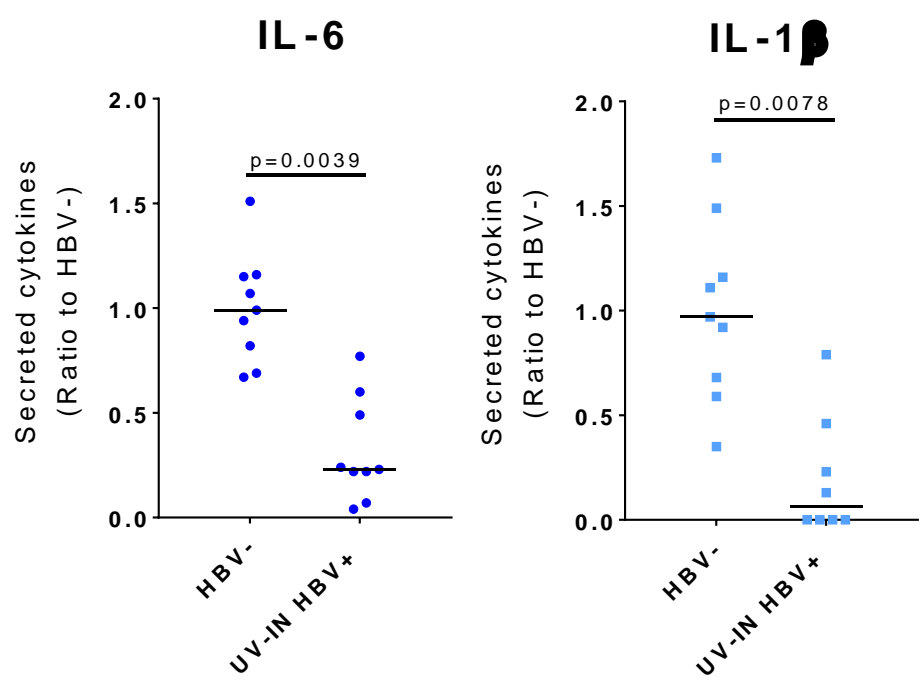

T N F -
IL -19

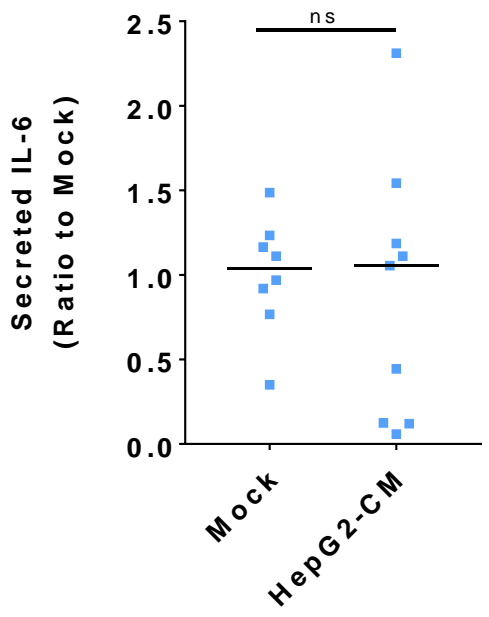

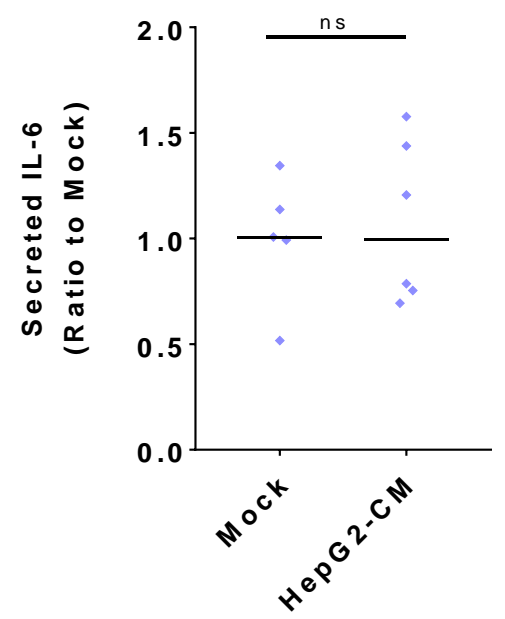

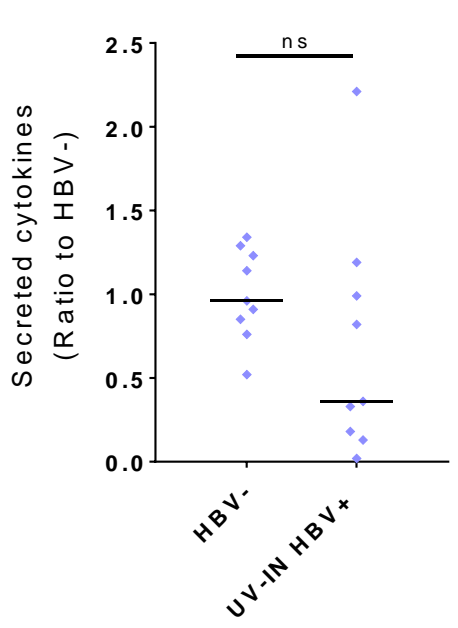

D. M2-MDM

$\mathrm{IL}-10$

TNF-C

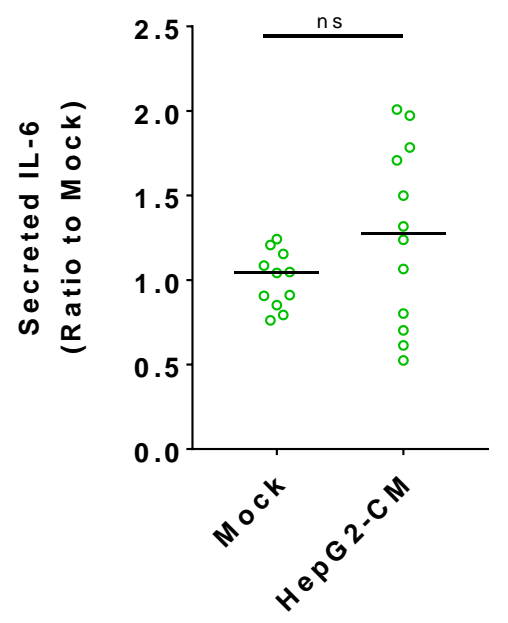

Supplementary figure 6: UV-inactivated HBV has similar effect as HBV on cytokines secretion by liver MФ and/or M1-MDM and concentrated medium from non-infected hepatocytes does not modified cytokines secretion. (A) Liver MФ were isolated from liver resection, exposed to medium (HBV-) or to an UV-inactivated HBV (UV-IN HBV+) for 24h, and stimulated with $100 \mathrm{ng} / \mathrm{ml}$ of LPS (TLR4-L) or $100 \mathrm{ng} / \mathrm{ml}$ of LPS $+100 \mathrm{ng} / \mathrm{ml}$ of Poly (dA:dT) (AIM2-L) for another 24h. (B,C,D) Monocytes were differentiated into M1MDM (upon GM-CSF culture) or M2-MDM (upon M-CSF culture) in the presence or not of (B) HBV inactivated with UV light or (C,D) concentrated medium of non-infected of HepG2 (HepG2-CM), during M1MDM differentiation and activation or during M2-MDM activation, before stimulation with $10 \mathrm{ng} / \mathrm{ml}$ of LPS for 3 hours. $(A, B, C, D)$ Cytokine levels were assessed by ELISA and analysed as ratio to non-exposed cells (HBVor Mock). Results are the median of one or four independent experiments (with one to four different donors) performed with three biological replicates. Horizontal bars represent the median and data were submitted to Wilcoxon test. 


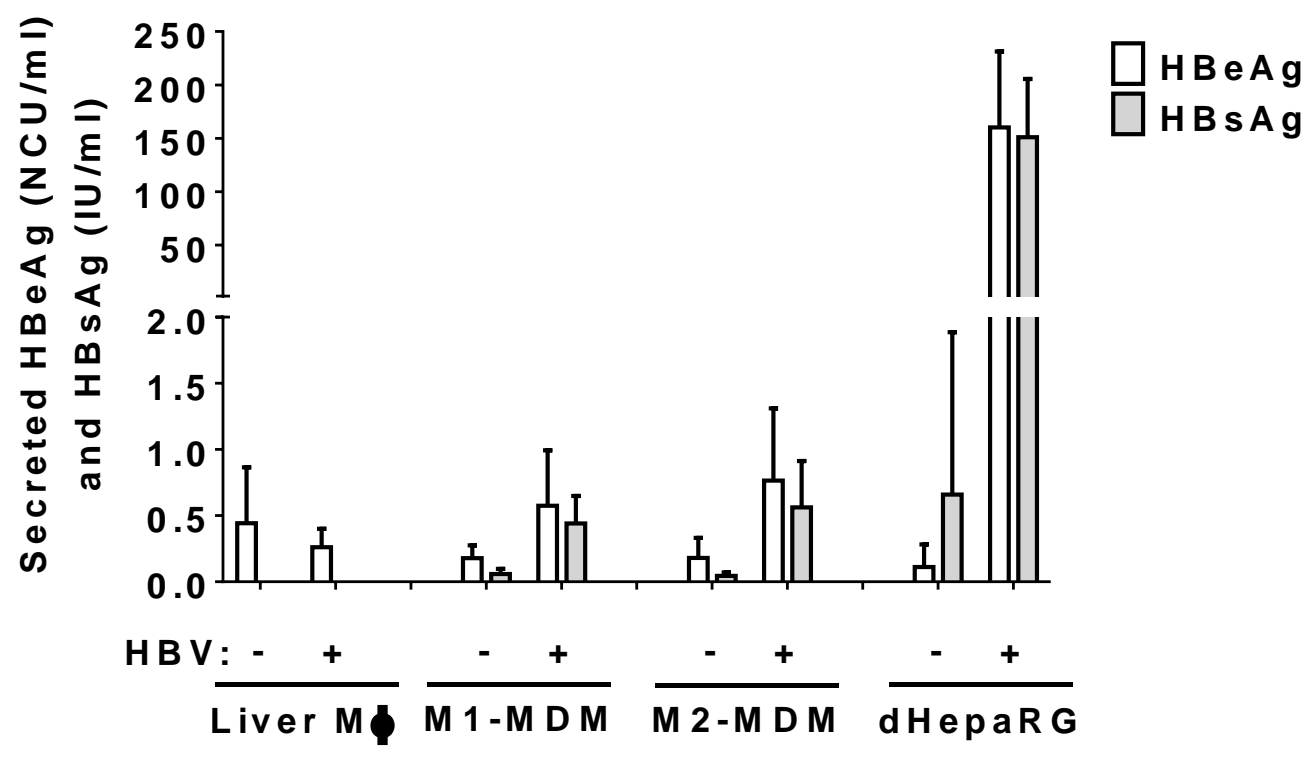

Supplementary figure 7: HBV did not replicate in macrophages. Liver $M \Phi$ and dHepaRG were exposed to HBV for one day and M1-MDM and M2-MDM for six days. Supernatant were collected and levels of HBeAg and HBsAg were determined by ELISA seven days post exposure. Data are presented as mean $+/$ - standard deviation of three independent experiments (three batches of dHepaRG and three different donors) each performed in three biological replicates. 
A.
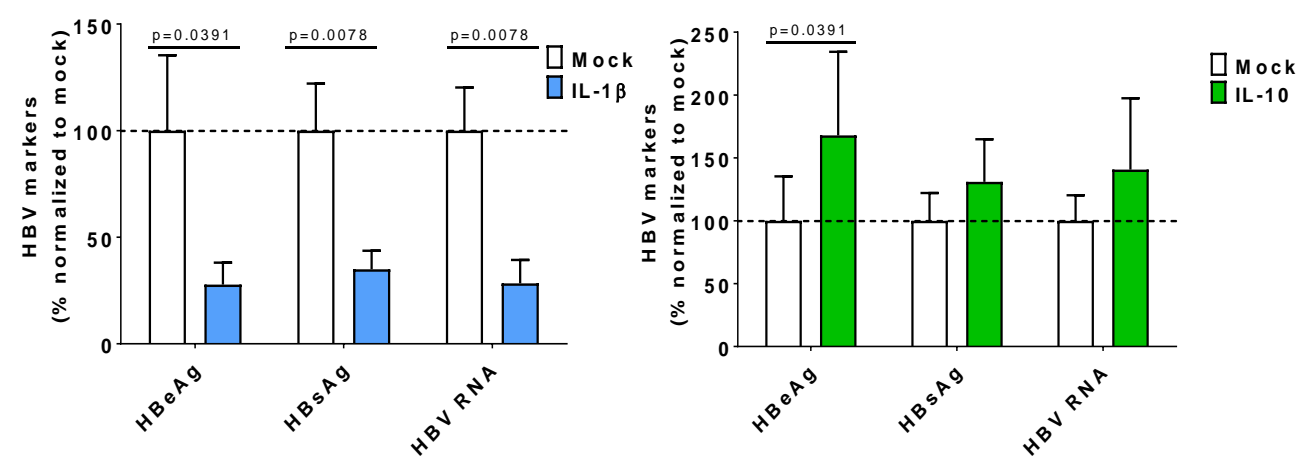

B.
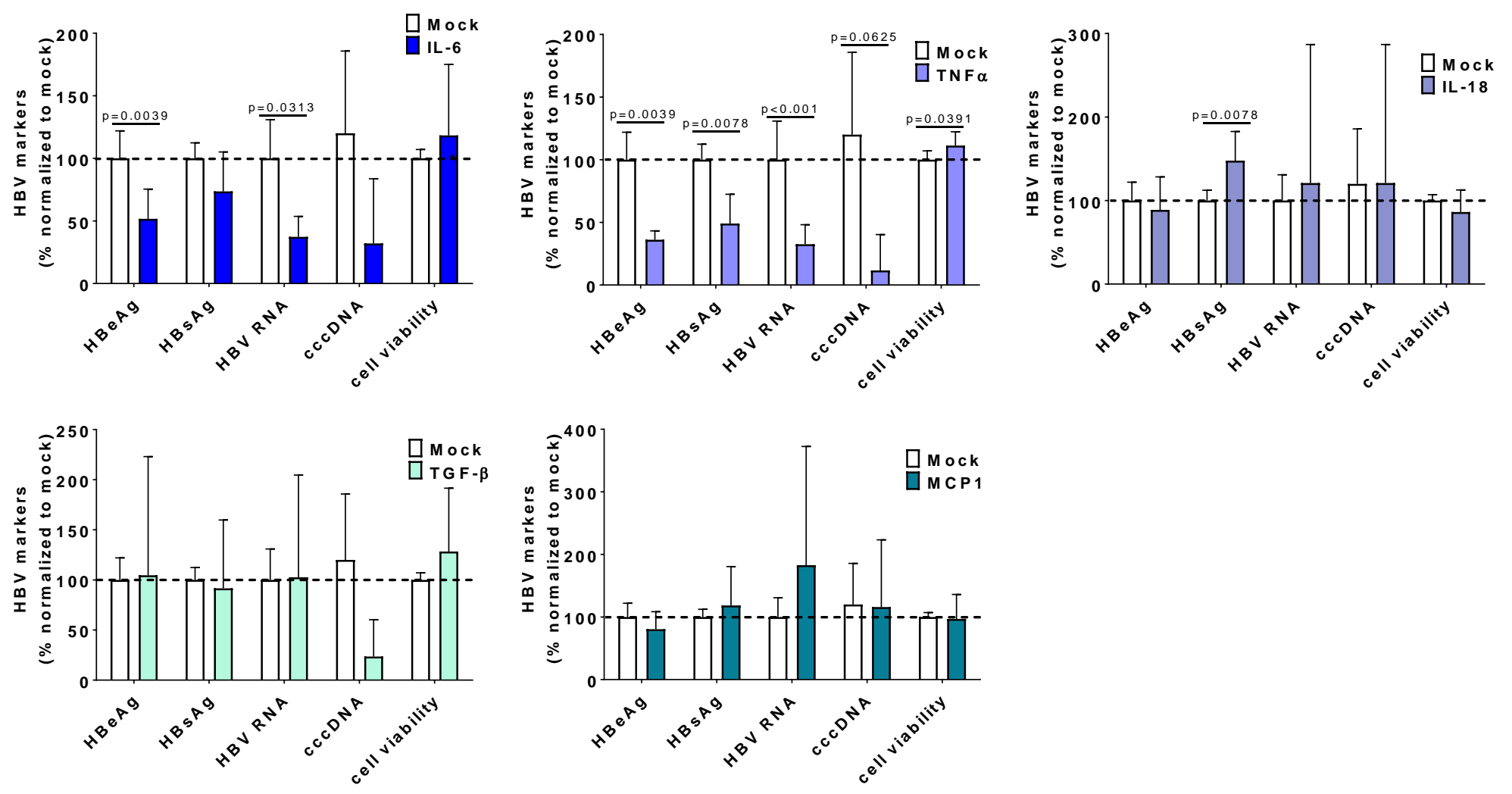

Supplementary figure 8: Effect of recombinant cytokines on the establishment of HBV infection.

Differentiated HepaRG cells were treated with the indicated recombinant cytokines (A) 24h before or (B) 24h before and during infection with HBV. $(A, B)$ Seven days post infection, supernatants were collected and levels of $\mathrm{HBeAg}$ and $\mathrm{HBsAg}$ were quantified by ELISA. Cells were harvest, total RNA or DNA were extracted and levels of HBV RNAs and cccDNA were quantified by RT-qPCR or qPCR analyses. Cell viability was assessed by neutral red uptake assay. Results, presented as ratio to non-treated cells, are the mean +/- standard deviation of three independent experiments each performed with three biological replicates. Data were submitted to Wilcoxon test. 

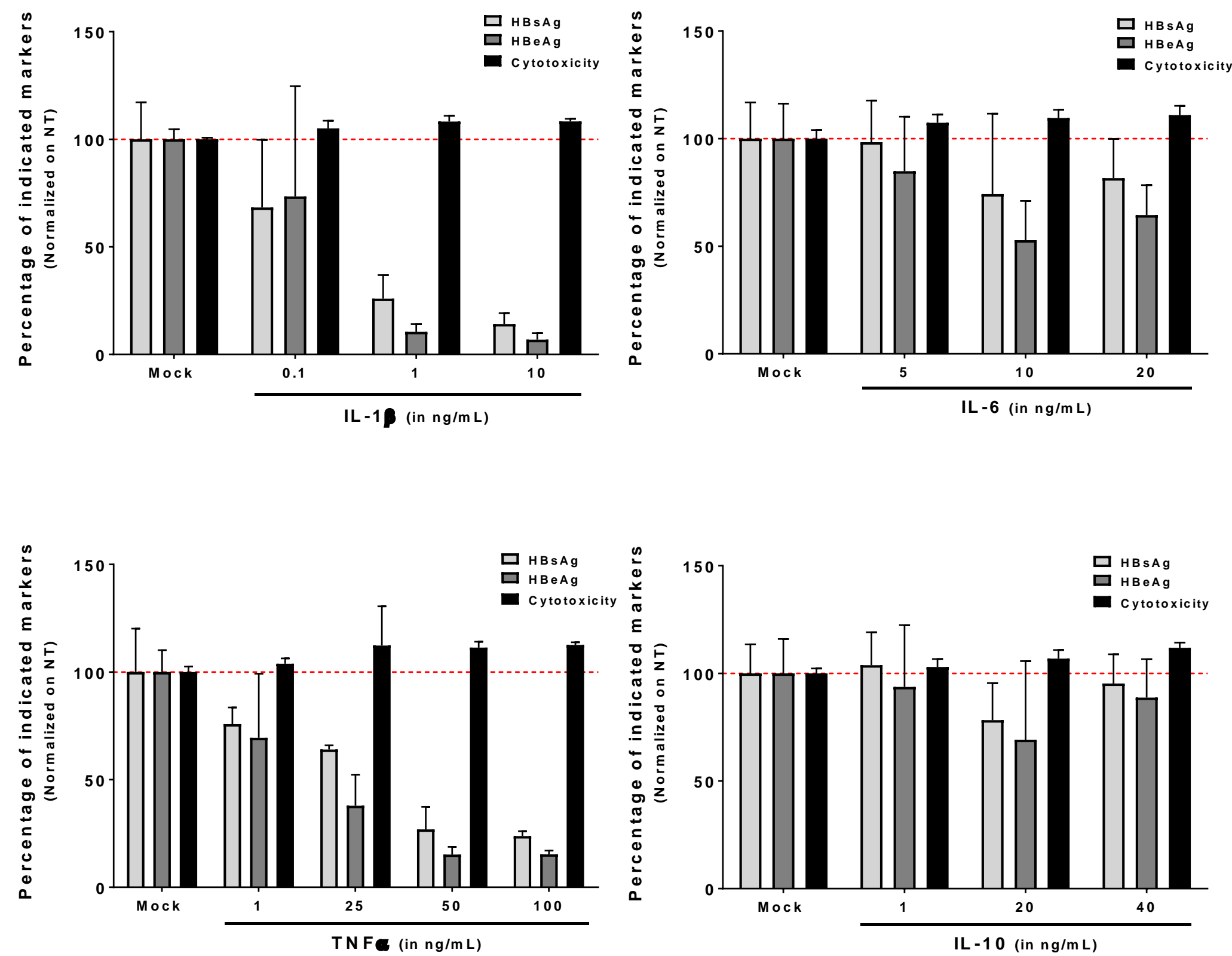

Supplementary figure 9: Dose response of recombinant cytokines on the establishment of HBV infection. Differentiated HepaRG cells were treated with the indicated recombinant cytokines $24 \mathrm{~h}$ before and during infection with HBV. Seven days post infection, supernatants were collected and levels of $\mathrm{HBeAg}$ and HBsAg were quantified by ELISA. Cell viability was assessed by neutral red uptake assay. Results, presented as ratio to non-treated cells, are the mean +/- standard deviation of two independent experiments each performed with three biological replicates. 
A.

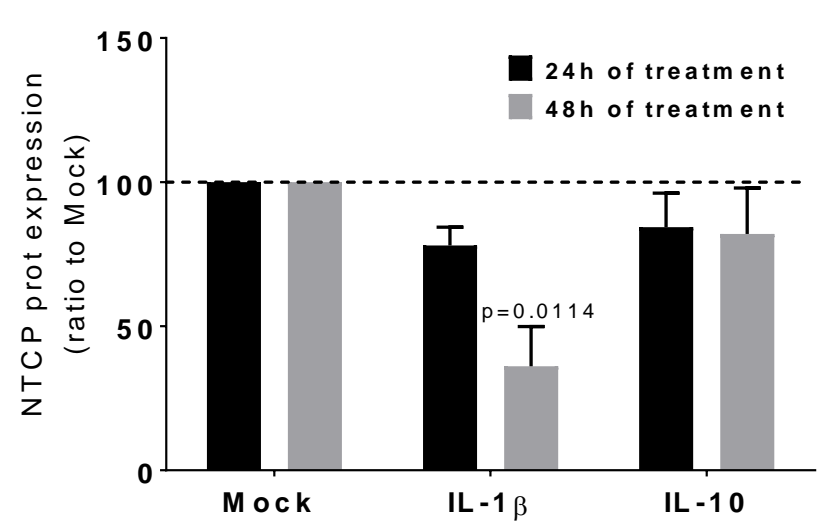

B.

PHH

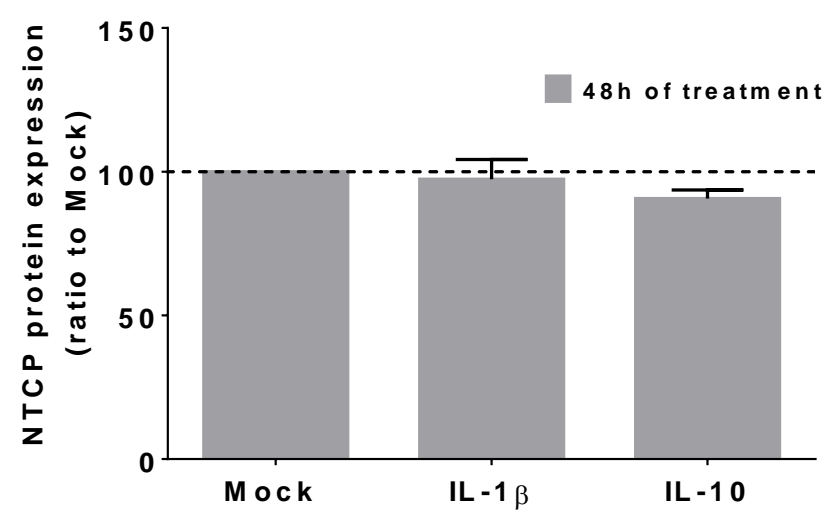

Supplementary figure 10: NTCP levels in dHepaRG and PHH treated with IL-1 $\beta$. (A) Differentiated HepaRG cells were treated with recombinant IL-1 $\beta$, and IL-10 for $24 \mathrm{~h}$ or $48 \mathrm{~h}$. (B) PHH were treated with recombinant IL-1 $1 \beta$, and IL-10 for $48 \mathrm{~h}$. (A-B) NTCP protein expression was analysed by flow cytometry. Results are presented in percentage normalised to the non-treated cells. Data are presented as mean $+/-\mathrm{SD}$ of three independent experiments (three batches of dHepaRG cells and three donors of PHH). Data were submitted to Kruskal Wallis test. 
Table S1. Patients characteristic of the Swiss/German cohort (livers biopsies analyzed by IHC). N: negative; P: positive.

\begin{tabular}{|c|c|c|c|c|c|c|c|c|c|}
\hline ID & Group & Pathology & $\begin{array}{c}\text { Grading } \\
\text { hepatitis* }\end{array}$ & $\begin{array}{c}\text { Staging } \\
\text { hepatitis* }\end{array}$ & $\begin{array}{c}\text { HBsAg (\% } \\
\text { hepatocytes) }\end{array}$ & $\begin{array}{l}\text { HBcAg } \\
(\mathrm{N} \text { or } \mathrm{P})\end{array}$ & $\begin{array}{l}\text { Delta-Antigen } \\
\text { ( } \mathrm{N} \text { or } \mathrm{P})\end{array}$ & $\begin{array}{l}\text { Fibrosis } \\
\text { (1 to } 4)\end{array}$ & $\begin{array}{c}\text { Necro- } \\
\text { inflammatory } \\
\text { activity } \\
\end{array}$ \\
\hline P\#1 & \multirow{13}{*}{$\begin{array}{l}\text { Non-infected } \\
\text { controls } \\
\text { (HC) }\end{array}$} & Moderate hepatitis & - & - & 0 & $\mathrm{~N}$ & $\mathrm{~N}$ & 1 & - \\
\hline P\#2 & & Unclear & - & - & 0 & $\mathrm{~N}$ & $\mathrm{~N}$ & - & - \\
\hline P\#3 & & Minimal steatohepatitis & - & - & 0 & $\mathrm{~N}$ & $\mathrm{~N}$ & - & - \\
\hline P\#4 & & $\begin{array}{l}\text { Severe sclerosing } \\
\text { steatohepatitis }\end{array}$ & - & - & 0 & $\mathrm{~N}$ & $\mathrm{~N}$ & - & - \\
\hline P\#5 & & $\begin{array}{c}\text { Sclerosing } \\
\text { steatohepatitis }\end{array}$ & - & - & 0 & $\mathrm{~N}$ & $\mathrm{~N}$ & - & - \\
\hline P\#6 & & $\begin{array}{c}\text { Moderate to high } \\
\text { sclerosing hepatitis }\end{array}$ & - & - & 0 & $\mathrm{~N}$ & $\mathrm{~N}$ & - & - \\
\hline P\#7 & & $\begin{array}{l}\text { High sclerosing } \\
\text { steatohepatitis } \\
\end{array}$ & - & - & 0 & $\mathrm{~N}$ & $\mathrm{~N}$ & - & - \\
\hline P\#8 & & $\begin{array}{c}\text { Moderate sclerosing } \\
\text { steatohepatitis }\end{array}$ & - & - & 0 & $\mathrm{~N}$ & $\mathrm{~N}$ & - & - \\
\hline P\#9 & & Minimal steatohepatitis & - & - & 0 & $\mathrm{~N}$ & $\mathrm{~N}$ & - & - \\
\hline P\#10 & & $\begin{array}{c}\text { Minimal sclerosing } \\
\text { steatohepatitis }\end{array}$ & - & - & 0 & $\mathrm{~N}$ & $\mathrm{~N}$ & - & - \\
\hline P\#11 & & $\begin{array}{c}\text { Moderate sclerosing } \\
\text { steatohepatitis }\end{array}$ & - & - & 0 & $\mathrm{~N}$ & $\mathrm{~N}$ & - & - \\
\hline P\#12 & & $\begin{array}{c}\text { Minimal sclerosing } \\
\text { steatohepatitis }\end{array}$ & - & - & 0 & $\mathrm{~N}$ & $\mathrm{~N}$ & - & - \\
\hline P\#13 & & $\begin{array}{l}\text { High sclerosing } \\
\text { steatohepatitis }\end{array}$ & - & - & 0 & $\mathrm{~N}$ & $\mathrm{~N}$ & 2 & - \\
\hline P\#14 & \multirow{26}{*}{$\begin{array}{l}\text { HBV-infected } \\
\text { patients } \\
\text { (HBV) }\end{array}$} & Chronic Hepatitis B & $\mathrm{H}-2$ & $\mathrm{H}-3-4$ & 20 & $\mathrm{~N}$ & $\mathrm{~N}$ & - & - \\
\hline P\#15 & & Chronic Hepatitis B & $1-3$ & $\mathrm{I}-1$ & 90 & $\mathrm{P}$ & $\mathrm{N}$ & 1 & 1 \\
\hline P\#16 & & Chronic Hepatitis B & $\mathrm{I}-3$ & $\mathrm{I}-2$ & $<5$ & $\mathrm{~N}$ & $\mathrm{~N}$ & - & - \\
\hline P\#17 & & Chronic Hepatitis B & I-3 & $1-3$ & $<1$ & $\mathrm{~N}$ & $\mathrm{~N}$ & - & - \\
\hline P\#18 & & Chronic Hepatitis B & $\mathrm{H}-2$ & $\mathrm{H}-2$ & 50 & $P$ & $\mathrm{~N}$ & - & - \\
\hline P\#19 & & Chronic Hepatitis B & $\mathrm{I}-5$ & $\mathrm{I}-2$ & 20 & $\mathrm{~N}$ & $\mathrm{~N}$ & 2 & 1 \\
\hline P\#20 & & Chronic Hepatitis B & I-3 & $\mathrm{I}-1$ & 10 & $\mathrm{~N}$ & $\mathrm{~N}$ & - & - \\
\hline P\#21 & & Chronic Hepatitis B & $\mathrm{I}-4$ & $\mathrm{I}-2$ & 60 & $\mathrm{~N}$ & $\mathrm{~N}$ & 2 & 1 \\
\hline P\#22 & & Chronic Hepatitis B & I-3 & $\mathrm{I}-1$ & 10 & $\mathrm{~N}$ & $\mathrm{~N}$ & 1 & 1 \\
\hline P\#23 & & Chronic Hepatitis B & $\mathrm{H}-2$ & $\mathrm{H}-3-4$ & 20 & $\mathrm{~N}$ & $\mathrm{~N}$ & - & - \\
\hline P\#24 & & Chronic Hepatitis B & $1-9$ & $1-6$ & 70 & $\mathrm{~N}$ & $\mathrm{~N}$ & - & - \\
\hline P\#25 & & Chronic Hepatitis B & $1-6$ & $1-6$ & $<1$ & $\mathrm{~N}$ & $\mathrm{~N}$ & 4 & 1 \\
\hline P\#26 & & Chronic Hepatitis B & I-3 & $\mathrm{I}-1$ & 5 & $\mathrm{~N}$ & $\mathrm{~N}$ & 2 & 1 \\
\hline P\#27 & & Chronic Hepatitis B & $1-7$ & $1-6$ & $>90$ & $P$ & $\mathrm{~N}$ & 4 & 2 \\
\hline P\#28 & & Chronic Hepatitis B & $\mathrm{I}-11$ & $1-3$ & 80 & $\mathrm{~N}$ & $\mathrm{~N}$ & 3 & 3 \\
\hline P\#29 & & Chronic Hepatitis B & $1-4$ & $\mathrm{I}-4$ & 80 & $\mathrm{~N}$ & $\mathrm{~N}$ & 1 & 1 \\
\hline P\#30 & & Chronic Hepatitis B & $\mathrm{I}-13$ & $1-6$ & 80 & $\mathrm{P}$ & $\mathrm{N}$ & 4 & 3 \\
\hline P\#31 & & Chronic Hepatitis B & $\mathrm{I}-2$ & $\mathrm{I}-1$ & 70 & $\mathrm{~N}$ & $\mathrm{~N}$ & 1 & 1 \\
\hline P\#32 & & Chronic Hepatitis B & $1-2$ & $\mathrm{I}-0$ & 90 & $\mathrm{~N}$ & $\mathrm{~N}$ & 0 & 1 \\
\hline P\#33 & & Chronic Hepatitis B & $\mathrm{I}-1$ & $\mathrm{I}-0$ & 95 & $P$ & $\mathrm{~N}$ & 0 & 1 \\
\hline P\#34 & & Chronic Hepatitis B & $1-2$ & $\mathrm{I}-1$ & 70 & $\mathrm{~N}$ & $\mathrm{~N}$ & 1 & 1 \\
\hline P\#35 & & Chronic Hepatitis B & $\mathrm{I}-2$ & $1-3$ & 5 & $\mathrm{~N}$ & $\mathrm{~N}$ & 3 & 1 \\
\hline P\#36 & & Chronic Hepatitis B & $1-6$ & $\mathrm{I}-2$ & 5 & $\mathrm{~N}$ & $\mathrm{~N}$ & 2 & 1 \\
\hline P\#37 & & Chronic Hepatitis B & $\mathrm{I}-2$ & $\mathrm{I}-2$ & 10 & $\mathrm{~N}$ & $\mathrm{~N}$ & 1 & 1 \\
\hline P\#38 & & Chronic Hepatitis B & $1-5$ & $1-5$ & 5 & $\mathrm{~N}$ & $\mathrm{~N}$ & 2 & 2 \\
\hline P\#39 & & Chronic Hepatitis B & $\mathrm{I}-10$ & $\mathrm{I}-4$ & 50 & $\mathrm{~N}$ & $\mathrm{~N}$ & 3 & 2 \\
\hline
\end{tabular}


Table S2. Patients characteristic from the French cohort (livers biopsies analyzed by IHC). N: negative; P: positive.

\begin{tabular}{|c|c|c|c|c|c|c|c|c|c|c|c|c|c|c|}
\hline ID & Group & Age & Sexe & Treatment & $\begin{array}{c}\text { HBsAg } \\
\text { (IU/mL) }\end{array}$ & $\begin{array}{l}\mathrm{HBeAg} \\
\text { ( } \mathrm{N} \text { or } \mathrm{P})\end{array}$ & $\begin{array}{l}\text { HBV DNA } \\
\text { (IU/mL) }\end{array}$ & cccDNA/cell & $\begin{array}{l}\text { Total HBV } \\
\text { DNA/cell }\end{array}$ & $\begin{array}{l}\text { rCDNA/ } \\
\text { cell }\end{array}$ & $\begin{array}{c}\text { Replicative } \\
\text { acitivity }\end{array}$ & $\begin{array}{c}\text { ALAT } \\
\text { (IU/ml) }\end{array}$ & $\begin{array}{l}\text { Fibrosis } \\
\text { (1 to 4) }\end{array}$ & $\begin{array}{c}\text { Necro-inflammatory } \\
\text { activity }\end{array}$ \\
\hline P\#1 & \multirow{4}{*}{$\begin{array}{l}\text { Healthy control } \\
\text { (HC) }\end{array}$} & 84 & $\mathrm{~F}$ & None & - & - & - & - & - & - & - & & & \\
\hline P\#2 & & 66 & $M$ & None & - & - & - & - & - & - & - & & & \\
\hline P\#3 & & 76 & $M$ & None & - & - & - & - & - & - & - & & & \\
\hline P\#4 & & 49 & $M$ & None & - & - & - & - & - & - & - & & & \\
\hline P\#5 & \multirow{14}{*}{$\begin{array}{l}\text { HBV infected } \\
\text { (HBV) }\end{array}$} & 23 & $\mathrm{~F}$ & None & 6511 & $\mathrm{~N}$ & 31 & 0,02 & 0,74 & 0,72 & 31,59 & 15 & 1 & 1 \\
\hline P\#6 & & 36 & $M$ & None & 1555 & $\mathrm{~N}$ & 50 & 0,09 & 12,09 & 11,99 & 127,86 & 42 & 1 & 0 \\
\hline P\#7 & & 42 & $\mathrm{~F}$ & None & 53,13 & $\mathrm{~N}$ & 86 & 0,03 & 0,71 & 0,68 & 20,50 & 35 & 0 & 1 \\
\hline P\#8 & & 59 & $M$ & None & 5926 & $\mathrm{~N}$ & 440 & 0,02 & 1,89 & 1,87 & 89,17 & 27 & 1 & 0 \\
\hline P\#9 & & 40 & $M$ & None & 10681 & $\mathrm{~N}$ & 541 & 0,08 & 5,54 & 5,45 & 65,07 & 65 & 1 & 0 \\
\hline P\#10 & & 42 & $M$ & None & 3250 & $\mathrm{~N}$ & 25238 & 0,41 & 3,09 & 2,68 & 6,58 & 78 & 3 & 1 \\
\hline P\#11 & & 42 & $\mathrm{M}$ & None & 1052 & $\mathrm{~N}$ & 27343 & 0,80 & 38,57 & 37,76 & 46,93 & 47 & 1 & 1 \\
\hline P\#12 & & 45 & $M$ & None & 1205 & $\mathrm{~N}$ & 17263 & 0,18 & 2,33 & 2,15 & 11,74 & 62 & 1,5 & 0 \\
\hline P\#13 & & 32 & $M$ & None & 26910 & $\mathrm{~N}$ & 93709 & 0,13 & 11,12 & 10,98 & 82,79 & 115 & 1 & 1 \\
\hline P\#14 & & 60 & $M$ & None & 7170 & $\mathrm{~N}$ & 1511762 & 0,34 & 3,75 & 3,41 & 10,12 & 45 & 1 & 1 \\
\hline P\#15 & & 28 & $M$ & None & 8069 & $\mathrm{P}$ & 32000000 & 6,35 & 4005,87 & 3999,52 & 629,75 & 68 & 1 & 1 \\
\hline P\#16 & & 34 & $M$ & None & 10539 & $\mathrm{P}$ & 139181 & 0,18 & 28,61 & 28,43 & 155,61 & 61 & 3 & 1 \\
\hline P\#17 & & 32 & $M$ & None & 66820 & $\mathrm{P}$ & 68275329 & 2,04 & 1975,58 & 1973,55 & 968,95 & 106 & 1 & 1 \\
\hline P\#18 & & 30 & $M$ & None & 8051 & $\mathrm{P}$ & 15800000 & 4,47 & 5734,49 & 5730,02 & 1281,31 & 75 & 2 & 1 \\
\hline
\end{tabular}




\begin{tabular}{|c|c|c|c|c|}
\hline $\begin{array}{l}\text { TARGET } \\
\text { PROTEIN }\end{array}$ & TYPE & COMPANY & $\begin{array}{l}\text { CATALOG } \\
\text { NUMBER }\end{array}$ & $\begin{array}{c}\text { NEGATIVE CONTROL } \\
\text { ANTIBODY }\end{array}$ \\
\hline CD163 & $\lg \mathrm{G} 1$ & Abcam & $a b 74604$ & Biolegend 400143 \\
\hline CD68 & $\lg G$ & Abcam & ab955 & Abcam ab18448 \\
\hline $\mathrm{HBc}$ & Polyclonal & $\begin{array}{l}\text { Diagnostic } \\
\text { Biosystems }\end{array}$ & RP 017-05 & \\
\hline $\begin{array}{l}\text { ANTI- } \\
\text { RABBIT }\end{array}$ & IgG/HRP & DAKO & P0448 & \\
\hline $\begin{array}{l}\text { ANTI- } \\
\text { MOUSE }\end{array}$ & IgG/HRP & DAKO & P0447 & \\
\hline NTCP & $\lg G$ & Abcam & $a b 175289$ & Secondary antibody only \\
\hline
\end{tabular}


Table S4. Recombinant cytokine references and working concentration

\begin{tabular}{ccc}
\hline Cytokine & Reference & Concentration \\
TNFa & Life Technologies PHC3016 & $50 \mathrm{ng} / \mathrm{ml}$ \\
IL-1 & MBL International Corporation JM4128-10 & $1 \mathrm{ng} / \mathrm{ml}$ \\
IL-6 & R\&D Systems 206-IL/CF & $10 \mathrm{ng} / \mathrm{ml}$ \\
IL-18 & MBL International Corporation B003-5 & $10 \mathrm{ng} / \mathrm{ml}$ \\
IL-10 & Biovision \# 4155-10 & $20 \mathrm{ng} / \mathrm{ml}$ \\
TGF- $\beta 1$ & Biovision \# 4342-5 & $5 \mathrm{ng} / \mathrm{ml}$ \\
MCP-1 & R\&D 279-MC-010 & $1 \mathrm{ng} / \mathrm{ml}$ \\
\hline
\end{tabular}


Table S5. Primers sequences

\begin{tabular}{ccc}
\hline GENE & FORWARD & REVERSE \\
\hline GUS & CGTGGTTGGAGAGCTCATTTGGAA & ATTCCCCAGCACTCTCGTCGGT \\
HBV & GGAGGGATACATAGAGGTTCCTTGA & GTTGCCCGTTTGTCCTCTAATTC \\
HBV cCCDNA & ATGGTGAGGTGAACAATGCT & GACTCTCTCGTCCCCTTCTC \\
RPLPO & CACCATTGAAATCCTGAGTGATGT & TGACCAGCCCAAAGGAGAAG \\
HIF1 $\boldsymbol{\alpha}$ & CCACCTCTGGACTTGCCTTT & CTCCATGGTGAATCGGTCCC \\
VEGF & AGGGCAGAATCATCACGAAGT & AGGGTCTCGATTGGATGGCA \\
\hline
\end{tabular}


Table S6. Supernatant from LPS-activated M2-MDM from one donor was collected and the indicated cytokines were determined by ELISA.

\begin{tabular}{ccc}
\hline MDM & \multicolumn{2}{c}{ M2 } \\
$\begin{array}{c}\text { Cytokines } \\
\text { (ng/ml) }\end{array}$ & HBV - & $\begin{array}{c}\text { HBV + } \\
\text { protocol 2 }\end{array}$ \\
IL-6 & 0 & 0 \\
IL-1 $\beta$ & 0,02 & 0,03 \\
IL-12 & 0 & 0 \\
TNF $\alpha$ & 0 & 0 \\
IL-10 & 3,3 & 5,7 \\
\hline
\end{tabular}


Table S7. Supernatant from LPS-activated M1-MDM from at least five different donors were pooled, concentrated by ultrafiltration and diluted in $\mathrm{dHepaRG}$ medium to the final concentration indicated.

\begin{tabular}{cccc}
\hline MDM & \multicolumn{3}{c}{ M1 } \\
$\begin{array}{c}\text { Cytokines } \\
(\mathbf{p g} / \mathrm{ml})\end{array}$ & HBV - & $\begin{array}{c}\text { HBV + } \\
\text { protocol 1 }\end{array}$ & $\begin{array}{c}\text { HBV + } \\
\text { protocol 2 }\end{array}$ \\
IL-6 & 1063 & 585 & 828 \\
IL-1 $\beta$ & 41 & 4 & 42 \\
TNFa & 1829 & 1492 & 1749 \\
IL-10 & 39 & 26 & 40 \\
\hline
\end{tabular}

